\title{
TABLE OF CONTENTS (TOC)
}

Authors are required to submit a graphic entry for the Table of Contents (TOC) in conjunction with the manuscript title. This graphic should capture the readers' attention and give readers a visual impression of the essence of the paper. Labels, formulae, or numbers within the graphic must be legible at publication size. Tables or spectra are not acceptable. Color graphics are highly encouraged. The resolution of the figure should be at least $600 \mathrm{dpi}$. The size should be at least $50 \mathrm{~mm} \times 80 \mathrm{~mm}$ with a rectangular shape (ideally, the ratio of height to width should be less than 1 and larger than 5/8). One to two sentences should be written below the figure to summarize the paper. To create the TOC, please insert your image in the template box below. Fonts, size, and spaces should not be changed.
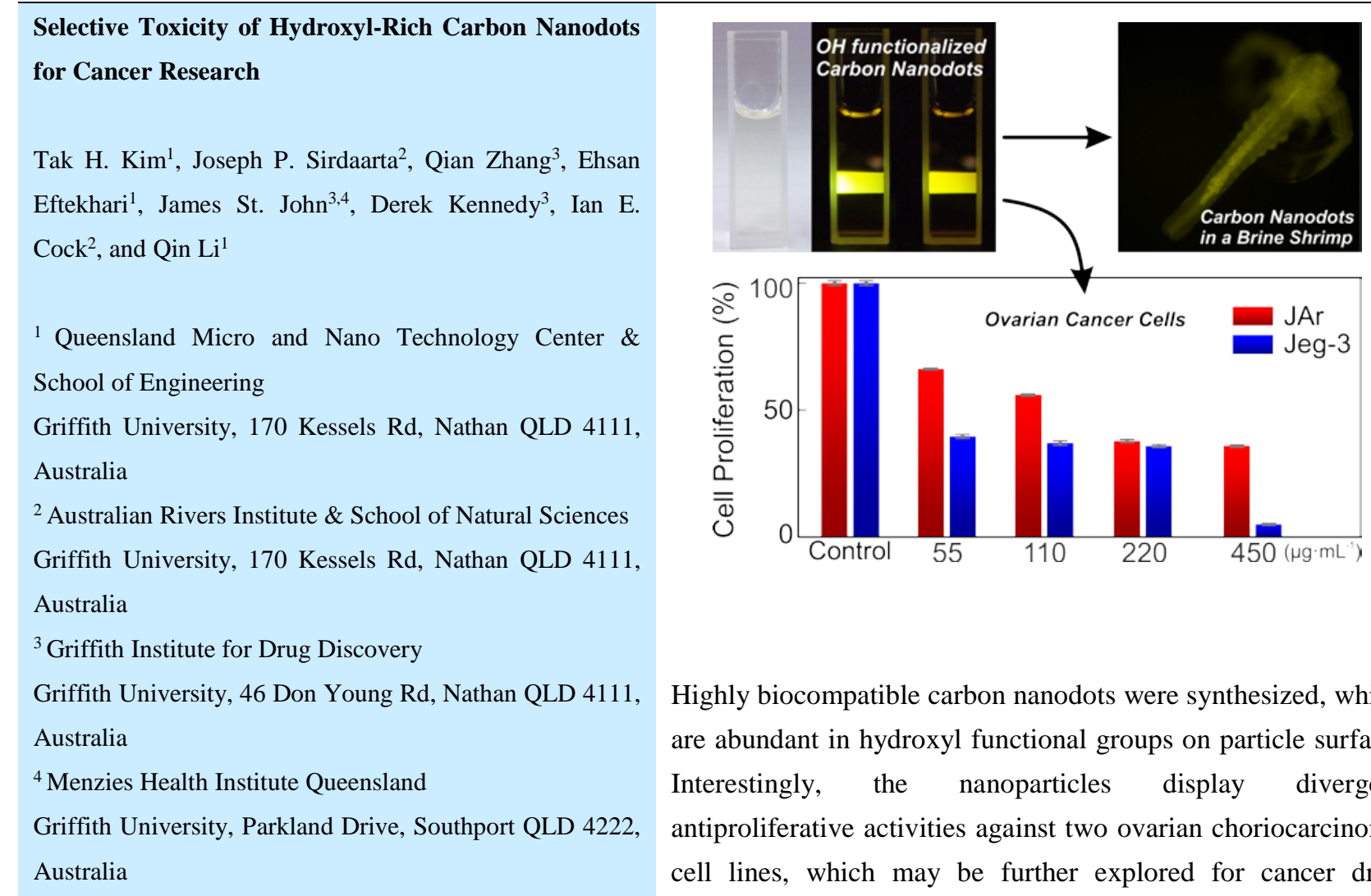

Highly biocompatible carbon nanodots were synthesized, which are abundant in hydroxyl functional groups on particle surface. Interestingly, the nanoparticles display divergent antiproliferative activities against two ovarian choriocarcinoma cell lines, which may be further explored for cancer drug discovery. 


\title{
Selective Toxicity of Hydroxyl-Rich Carbon Nanodots for Cancer Research
}

\author{
Tak H. Kim ${ }^{1}$, Joseph P. Sirdaarta ${ }^{2}$, Qian Zhang ${ }^{3}$, Ehsan \\ Eftekhari $^{1}$, James St. John ${ }^{3,4}$, Derek Kennedy ${ }^{3}$, Ian E. \\ Cock $^{2}$, and Qin Li' $(\bowtie)$ \\ ${ }^{1}$ Queensland Micro and Nano Technology Center \& School of \\ Engineering, Griffith University, 170 Kessels Rd, Nathan QLD 4111, \\ Australia \\ ${ }^{2}$ Australian Rivers Institute \& School of Natural Sciences, Griffith \\ University, 170 Kessels Rd, Nathan QLD 4111, Australia \\ ${ }^{3}$ Griffith Institute for Drug Discovery, Griffith University, 46 Don \\ Young Rd, Nathan QLD 4111, Australia \\ ${ }^{4}$ Menzies Health Institute Queensland, Griffith University, Parkland \\ Drive, Southport QLD 4222, Australia
}

Received: day month year / Revised: day month year / Accepted: day month year (automatically inserted by the publisher)

(C) Tsinghua University Press and Springer-Verlag Berlin Heidelberg 2011

\begin{abstract}
The toxicity of nanoparticles in a biological system is an integration of effects arising from surface functionality, particle size and ionic dissolution etc. Its complexity suggests that generalization on a material's toxicity may be inappropriate. Moreover, from medicinal point of view, toxicity can be used for treatment of malignant cells, such as cancer. In this study, highly biocompatible carbon nanodots (named gCDs) were synthesized by reacting citric acid and urea in glycerol, which resulted in abundant hydroxyl functional groups on particle surface. gCDs show excitation-dependent photoluminescence, but with brighter green to yellow emission. Importantly, a series of toxicity assessments showed that as-synthesized gCDs possess exceptional biocompatibilities to various biological entities including 18 bacteria species, Petunia axillaris seedlings and Artemia franciscana nauplii. Furthermore, the particles were shown to have low- to non-toxic effects on human embryonic kidney (HEK-293) cell lines, breast (MCF-7), oral squamous (CAL-27) carcinoma cell lines. Of particular interest, the gCDs display antiproliferative activities against ovarian choriocarcinoma cells (JAr / Jeg-3 cell lines), which may be further explored for cancer drug discovery.
\end{abstract}

\section{KEYWORDS}

carbon nanodots, fluorescence, nanotoxicity, choriocarcinoma cells, thioredoxin reductase 


\section{Introduction}

Nanoparticles have been envisaged to provide localized cure for challenging diseases, such as cancer, by facilitating targeted delivery and

Address correspondence to Qin Li, qin.li@griffith.edu.au

improved bioavailability. The functionalized nanoparticles can either act as the vehicle for potent drugs or they themselves can act as the therapeutic agents[1]. Carbon dots (CDs) have attracted significant research interest in the past decade owing to their excellent optical performance, low toxicity, chemical stability and flexibility and versatility in synthesis[2]. Their bright and tunable fluorescence has prompted development of CDs for a wide range of applications including biological imaging[3,4], sensing[5], solid state lighting[6,7], and drug delivery[8,9]. At its inception, CDs were generally deemed as biocompatible and of low-toxicity to nontoxic[10]. However, caution should be exercised in generalizing this conclusion. Numerous new methods with novel recipes have been developed for synthesizing CDs with improved optical properties, diverse functionalities and easier methods[11,12]. Since the interactions of nanoparticles with biological systems are an integration of effects arising from surface functionality, particle size and ionic dissolution, the toxicity of CDs needs to be evaluated case by case, instead of being generalized. On the other hand, effects on the inhibition of cellular proliferation may provide leads for drug discovery. Overall, a comprehensive understanding of the toxicity of CDs in various biological systems are required for validating the use of CDs' for further in vivo and in vitro studies.

Significant research efforts have also been made on tuning the emission colors[5,13], and understanding the fluorescence mechanisms[14] of CDs. Most of the reported CDs emit blue[15] or green fluorescence[10], which limits their broad applications, particularly in bioimaging. Although exact answers are not yet available, a consensus has been reached that in the case of CDs the surface states (both density and moiety) have a stronger influence on the emissive properties than particle size does[13,14]. To establish a better understanding of the relationship between surface states and emission properties, comparative studies with a variety of ligands on the surface of similar CDs are

required.

Herein, we report a new type of $C D$ that is synthesized by a hydrothermal reaction with citric acid and urea in glycerol, named gCDs. The resultant gCDs exhibit red-shifted PL emission, in comparison to CDs synthesized in water using the same synthetic method and precursors (wCDs)[16]. Interestingly, the gCDs were completely non-toxic to plants (Petunia axillaris seedlings), brine shrimps (Artemia franciscana nauplii) and several bacterial species, which is opposite to the outcome of wCDs. The gCDs exhibited nontoxic to low toxicity towards HEK-293 cells, MCF-7 and CAL-27 carcinoma cells. In contrast, the gCDs exhibited antiproliferative activities towards the ovarian choriocarcinoma cells, JAr/Jeg-3, which over-produce thioredoxin[17,18]. The study offers new insight into the in vivo and in vitro biological activities of gCDs. The selective antiproliferative activities displayed on the aggressive ovarian choriocarcinoma cells, JAR, is deserves attention and may offer a new drug lead or scaffold for the development of cancer chemotherapeutics.

\section{Results and Discussion}

\subsection{Synthesis}

The CD samples were prepared by a one-step hydrothermal method. Urea and citric acid were mixed in a $10: 1$ molar ratio (0.5 g urea and $0.16 \mathrm{~g}$ citric acid) in $10 \mathrm{~mL}$ of glycerol. The mixture was placed in a hydrothermal reactor, followed by a 24-hour reaction at $180^{\circ} \mathrm{C}$ (CDs samples synthesized in water, wCDs, were prepared for control experiments and results for ${ }^{\prime} C D$ s are available in Supplementary Material). The formation of CDs in a hydrothermal system has been recognized as a 

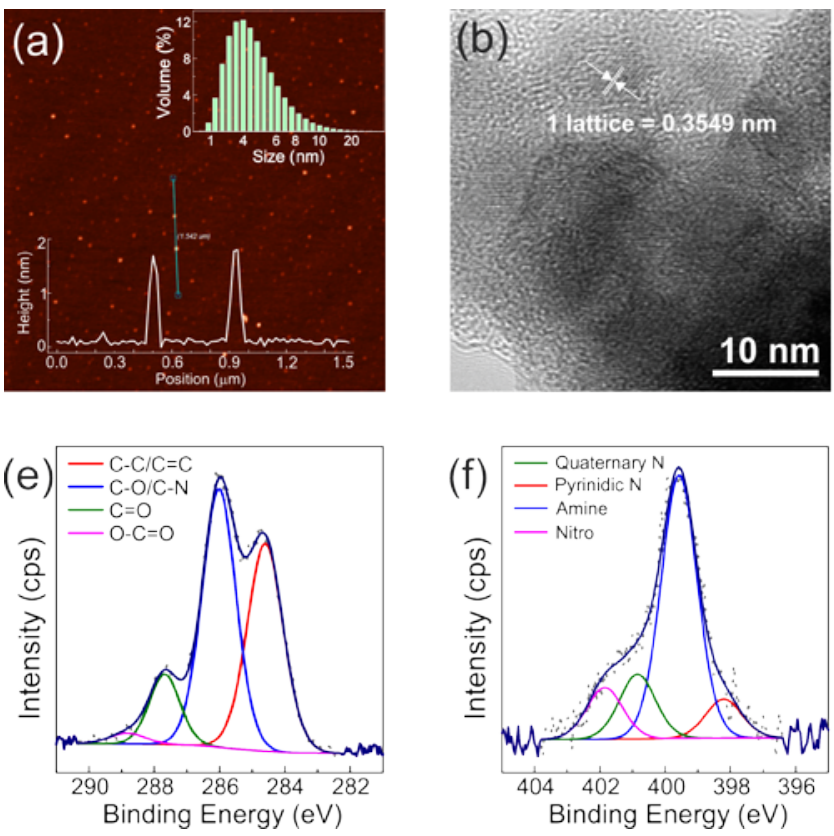

carbonization of the precursors which is considered a complex route, involving dehydration and polymerization stages[19,20]. Urea decomposes into ammonia and carbon dioxide gas under the reaction conditions, whilst citric acid forms the backbone of the CDs' framework. It has been established that pressurized ammonia gas can achieve both $\mathrm{N}$ doping
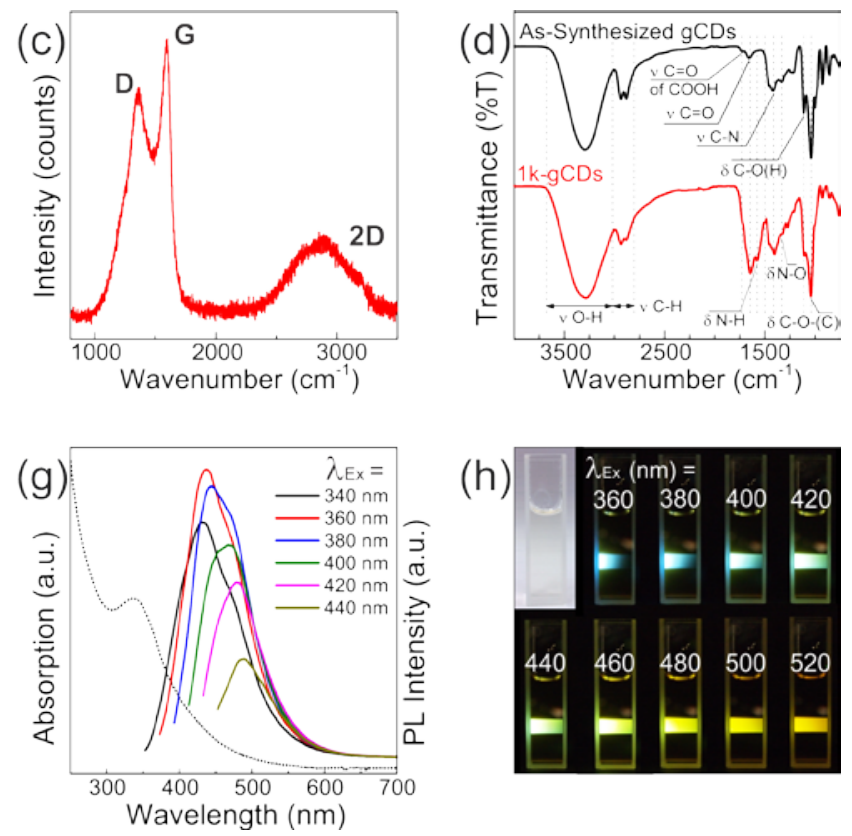

in the conjugated carbon structure and amine surface functionalization[21]. Additionally, adding hydroxyl rich glycerol into the system results in hydroxylamine formation, followed by reduction of the imine[22,23]. During the reaction, polymerization proceeds, resulting in nucleation and nanoparticles growth by aggregation[24]. The crude as-synthesized

Figure 1 (a) Atomic force microscopy images (Inset: DLS), (b) HRTEM image and (c) Raman spectrum of 1k-gCDs; (d) IR comparison between as-synthesized and 1k-gCDs, high resolution (e) C1s, (f) N1s XPS spectrum of the 1k-gCDs, (g) UV-Vis absorption and PL emission of $1 \mathrm{k}$-gCDs, (h) pictures of 1k-gCDs PL emission under room light and various excitations. The corresponding data of the 3.5k-gCDs are available in Supplementary Material.

CDs were further processed and purified via dialysis at $3.5 \mathrm{kD}$ (3.5k-gCDs) and $1 \mathrm{kD}$ (1k-gCDs), respectively (The sample preparation processes are illustrated in Scheme S1).

\subsection{Physiochemical properties}

The CDs' particle sizes were characterized by atomic force microscopy (AFM) and dynamic light scattering (DLS). As presented in Figure 1 (a), the majority of particles collected from $1 \mathrm{kD}$ membrane (1k-gCDs) were measured between 1 and $4 \mathrm{~nm}$ by AFM. The size distribution from the DLS measurement was in agreement (Figure 1 (a) inset). However, the distribution from DLS was slightly larger with particles reaching up to $20 \mathrm{~nm}$. The relative increase in particle distribution in the DLS is likely attributable to the hydration layer from the peripheral functionality and the agglomeration of the particles. The surface charge of the gCDs determined by the DLS measurement is $-15 \mathrm{mV}$, whilst the $\mathrm{wCDs}$ exhibited almost neutral charge $(-1 \mathrm{mV})$.

TEM characterization in Figure 1 (b) indicates that the particles are spherical with multiple carbon layers. Successive planes of carbon lattices can be observed and the distance between successive planes is $\sim 0.36 \mathrm{~nm}$. The Raman spectrum of the $1 \mathrm{k}-\mathrm{gCDs}$ (Figure 1 (c)) displayed two notable peaks at 1368 and $1595 \mathrm{~cm}^{-1}$ corresponding to the D and G band, respectively. The broad 2D band between 2700 and $2800 \mathrm{~cm}^{-1}$, with a strong $\mathrm{G}$ band intensity, further indicates that the particles contain multiple graphitic layers[25]. The weak shoulder at $1549 \mathrm{~cm}^{-1}$ from the asymmetric $G$ band may indicate the presence of 
structural defects and/or oxidized products on the surface of the particles[26].

The Infrared (IR) spectra in Figure 1 (d) indicate that all of the gCDs have strong hydroxyl $\left(3600-3200 \mathrm{~cm}^{-1}\right.$ stretch) bands. The $\mathrm{C}=\mathrm{O}$ and $\mathrm{C}-\mathrm{N}$ stretches between 1750 and $1550 \mathrm{~cm}^{-1}$ from the as-synthesized gCDs confirms the formation and functionalization of the carbon nanoparticles. Both the as-synthesized and $1 \mathrm{k}-\mathrm{gCDs}$ show relatively strong stretch $\mathrm{O}-\mathrm{H}$ (3600-3200 $\left.\mathrm{cm}^{-1}\right)$ and C-H stretch (3000-2750 $\left.\mathrm{cm}^{-1}\right)$ due to the hydroxyl rich environment (glycerol as a solvent) for the synthesis. These strong $\mathrm{C}-\mathrm{H}$ and $\mathrm{O}-\mathrm{H}$ bands indicate the incorporation of glycerol on $\mathrm{CDs}$ surface via esterification or hydroxylamine formation[27], affording multiple hydroxyls on the particle surface. Furthermore, the $1 \mathrm{k}-\mathrm{gCDs}$ display relatively stronger $\mathrm{C}=\mathrm{O}$ stretch (1780 and $1655 \mathrm{~cm}^{-1}$ ) and $\mathrm{N}-\mathrm{H}$ bend $\left(1565 \mathrm{~cm}^{-1}\right)$ than the as-synthesized $\mathrm{CDs}$, indicating the existence of other functional groups such as carboxyl and amine. The $\mathrm{C}-\mathrm{N}$ stretch at $1400 \mathrm{~cm}^{-1}$ further supports the functionalization of amine on the surface of the carbon cores[28]. Furthermore, the $\mathrm{N}-\mathrm{O}$ bend with the overlapping $\mathrm{N}-\mathrm{O}$ stretch at 1300 and $1510 \mathrm{~cm}^{-1}$ respectively further confirms the formation of hydroxylamine in glycerol, similar to other systems reported[22,23].

The samples were further characterized by $x$-ray photoelectron spectroscopy (XPS) to probe the chemical structures of the core and the surface functionalities. The XPS survey spectrum of the $1 \mathrm{k}-\mathrm{gCD}$ indicates that the $1 \mathrm{k}-\mathrm{gCD}$ primarily consist of carbon $(\sim 67 \%)$. Oxygen and nitrogen contents were 27 and 6\% respectively (Figure S4 and Table S1). The high resolution C1s spectra (Figure 1 (e)) could be deconvoluted into four peaks corresponding to $\mathrm{C}-\mathrm{C} / \mathrm{C}=\mathrm{C}(284.6 \mathrm{eV}), \mathrm{C}-\mathrm{O} / \mathrm{C}-\mathrm{N}(286.0 \mathrm{eV}), \mathrm{C}=\mathrm{O}(287.6$ $\mathrm{eV})$ and $\mathrm{O}-\mathrm{C}=\mathrm{O}(288.6 \mathrm{eV})[29]$. The distinctively large amount of C-O/C-N indicates rich surface functionalities due to the participation of urea and glycerol in reaction. The high resolution spectra of N1s in Figure 1 (f) revealed four peaks at 398.4, 399.6, 401.1 and $402.3 \mathrm{eV}$ ascribed to pyridinic $\mathrm{N}$, amine, quaternary $\mathrm{N}$ and nitro from hydroxylamine respectively[30,31]. The presence of nitro functionality from XPS additionally supports the formation of hydroxylamine. Furthermore, the pyridinic $\mathrm{N}$ in the gCDs demonstrates $\mathrm{N}$-doping in the carbon ring structure during hydrothermal reaction.

The oxygen containing functional groups present in glycerol (hydroxyl) and citric acid (carboxyl) may interact with the amines in urea, contributing to the incorporation of $\mathrm{N}$ into the carbon nanoparticles through the hydroxylamine and imine formation followed by transformation of imine[22,23,32] to pyridinic $\mathrm{N}$ during carbonization on the $\mathrm{gCDs}[33,34]$. In comparison, the reaction in the absence of glycerol but water may have resulted in the decomposition of urea and the formation of carbon nitride and ammonia, which would act as an intermediate for the formation of a N dopant in the carbon core[35]. This would results in rich amines on the surface of wCDs (Figure S5)[16]. The results from XPS correlate well with the data from IR characterizations.

UV-Vis characterizations in Figure 1 (g) reveal the characteristic properties of gCDs. The absorption edge indicate that the samples have absorption maxima shorter than $250 \mathrm{~nm}$, which can be ascribed to $\pi-\pi^{*}$ transition. Shoulder peaks at $\sim 340 \mathrm{~nm}$, adjacent to its absorption edge due to $\mathrm{n}-\pi^{*}$ transition, are also noted. ${ }^{45}$ PL spectra of the $1 \mathrm{k}$-gCDs in Figure 1 (g) display excitation dependent PL emission spectra similar to previous reports. Yellow PL emission was also noted when the $1 \mathrm{k}-\mathrm{gCDs}$ are excited over the blue spectral range (e.g. $460 \mathrm{~nm}$, Figure 1 (h) and Figure S6). Notable red-shifts were also observed from 3.5k-gCDs $\left(\lambda_{\mathrm{Em}}=520 \mathrm{~nm}\right.$ for $1 \mathrm{k}-\mathrm{gCDs} ; c f . \lambda_{\mathrm{Em}}=550 \mathrm{~nm}$ for $3.5 \mathrm{k}-\mathrm{gCDs}$ at $\lambda_{\mathrm{Ex}}=460$ nm, Figure S6). These red shifts of PL emission are highly likely caused by the larger particle size (1 - 10 nm 1k-gCDs; cf. 4 - 20 nm 3.5k-gCDs, Figure S1)[36]. Quantum yields of the $1 \mathrm{k}-\mathrm{gCD}$ were measured at $10 \%\left(\lambda_{\mathrm{Ex}}=360 \mathrm{~nm}\right)$.

\subsection{Toxicity assessment}

The toxicity of the gCDs were assessed against various biological entities including bacteria, brine shrimps (Artemia franciscana nauplii), Petunia axillaris seedlings, human embryonic kidney (HEK-293) cell 

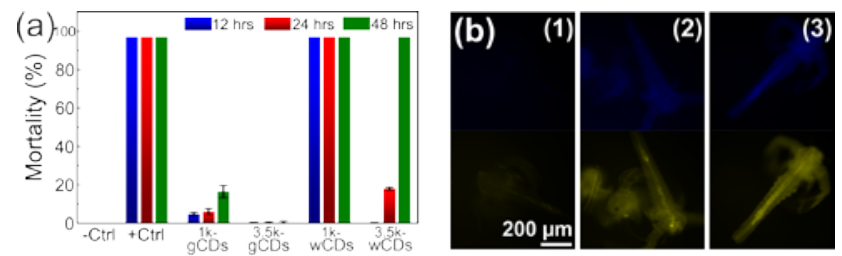

(c)
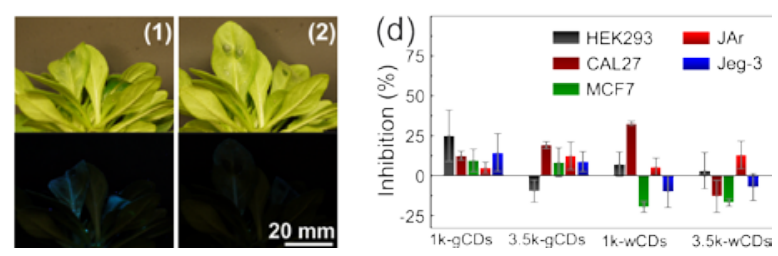

lines, breast (MCF-7), oral squamous (CAL-27) carcinoma cell lines and ovarian choriocarcinoma (JAr / Jeg-3) cell lines. 1k- and 3.5k-wCDs were also tested under identical conditions for comparison.

The CDs' antibacterial activities were assessed by Kirby-Bauer antibiotic test, which showed no antibacterial activities for neither gCDs nor wCDs (Table S2). However, when assessed against Artemia franciscana nauplii (brine shrimps) lethality bioassay at a concentration of $1.5 \mathrm{mg} \cdot \mathrm{mL}^{-1}$ [37]. None of the gCDs displays noticeable toxic effect whilst the wCDs show mortalities comparable with the reference toxin (potassium dichromate, $1 \mathrm{mg} \cdot \mathrm{mL}^{-1}$ ), as shown in Figure 2 (a). Fluorescence microscopy

Figure 2 (a) Mortality of the CDs tested against brine shrimps, (b) fluorescence microscopy images of brine shrimps ((1) negative control, (2) 1k-gCDs and (3) 3.5k-gCDs, top: $\lambda_{\mathrm{Ex}}=405$ and bottom: $\lambda_{\mathrm{Ex}}=488 \mathrm{~nm}$ ), (c) $1 \mathrm{k}$-gCDs infiltrated into Petunia axillaris seedling leaves ((1) after $10 \mathrm{~m}$ and (2) after $2 \mathrm{~h}$, top: room light and bottom: $365 \mathrm{~nm}$ UV light) and (d) cell viability assessed at $450 \mu \mathrm{g} \cdot \mathrm{mL}^{-1} \mathrm{CD}$ concentration after $24 \mathrm{~h}$ incubation.

images of the brine shrimps in Figure 2 (b) clearly show uptake and distribution of the sample within the brine shrimps whilst the images from the control group show no obvious visuals. The brine shrimps incubated in synthetic seawater doped with $1 \mathrm{k}-\mathrm{gCD}$ and $3.5 \mathrm{k}-\mathrm{gCDs}$ for $48 \mathrm{hrs}$, respectively, were clearly photoluminescent, confirming the uptake of the gCDs by the brine shrimps.

The toxicity of $1 \mathrm{k}-\mathrm{gCD}$ and $1 \mathrm{k}-\mathrm{wCD}$ samples were further tested by infiltrating the $1 \mathrm{k}-\mathrm{CD}$ on Petunia axillaris seedlings[38]. The CD samples in the leaf show visible emission under a 365nm UV lamp (Figure 2 (c), S7 and S8). The petunia axillaris seedling injected with $1 \mathrm{k}$-gCDs did not show any noticeable toxic effects. The leaf infiltrated by the $1 \mathrm{k}-\mathrm{gCD}$ s was devoid of signs of dehydration or abnormality and the leaf returned to normal condition within 1 hour. The emission from the leaf could not be observed after one day. The seedling was observed for four weeks and showed no obvious toxic effects. This indicates that the infiltrated $1 \mathrm{k}-\mathrm{gCDs}$ were metabolized by the Petunia axillaris seedling. However, the leaf infiltrated by the $1 \mathrm{k}-\mathrm{wCD}$ showed signs of dehydration after 2 hours, resulting in complete dehydration after 24 hours (Figure S8). Another set of assessments were performed by feeding the $1 \mathrm{k}-\mathrm{gCD}$ and $1 \mathrm{k}-\mathrm{wCD}$ directly to the Petunia axillaris seedlings for four weeks. No visible signs of toxicity were observed. No further effects on the growth were observed compared with the control sample (Figure S9, S10 and S11). However, the seedling grown in the presence of the CDs showed higher luminescent under UV.

The gCDs are rich in hydroxyl groups whilst the ${ }_{w C D s}$ have relatively higher amounts of amine and carboxyl. Therefore, the mortality caused by the ${ }_{w C D s}$ is likely originated from the amine/carboxyl on the surface, which can have strong interactions with biological entities[39]. In contrast, the benignity of gCDs could be attributed to the rich hydroxyls on the particle surface and the overall negative charge $(-15 \mathrm{mV})$.

In vitro toxicity was assessed on HEK293, CAL27 and MCF7 using an alamarBlue cell viability assay and JAr and Jeg-3 via an MTS assay system at an initial CD concentration of $450 \mu \mathrm{g} \cdot \mathrm{mL}^{-1}$. The results in Figure 2 (d) indicate that none of the CD samples displayed notable toxic effects (dose responses Figure S12). Interestingly, introducing the $1 \mathrm{k}$-gCDs prior to the cell adhesion (shorter incubation periods) resulted in inhibition of cellular proliferation, evidenced by the results from both the MTT and alamarBlue assays (Figure S12 (e) and Figure 3 (a) respectively). The results from the JAr and Jeg-3 cell assays were particularly interesting, displaying substantial inhibition of cellular proliferation. Indeed, when dosed with $450 \mu \mathrm{g} \cdot \mathrm{mL}^{-1} 1 \mathrm{k}-\mathrm{gCD}$ prior to cell adhesion, the JAr and Jeg-3 cell proliferation was reduced $35 \%$ and $5 \%$, respectively, as shown in 

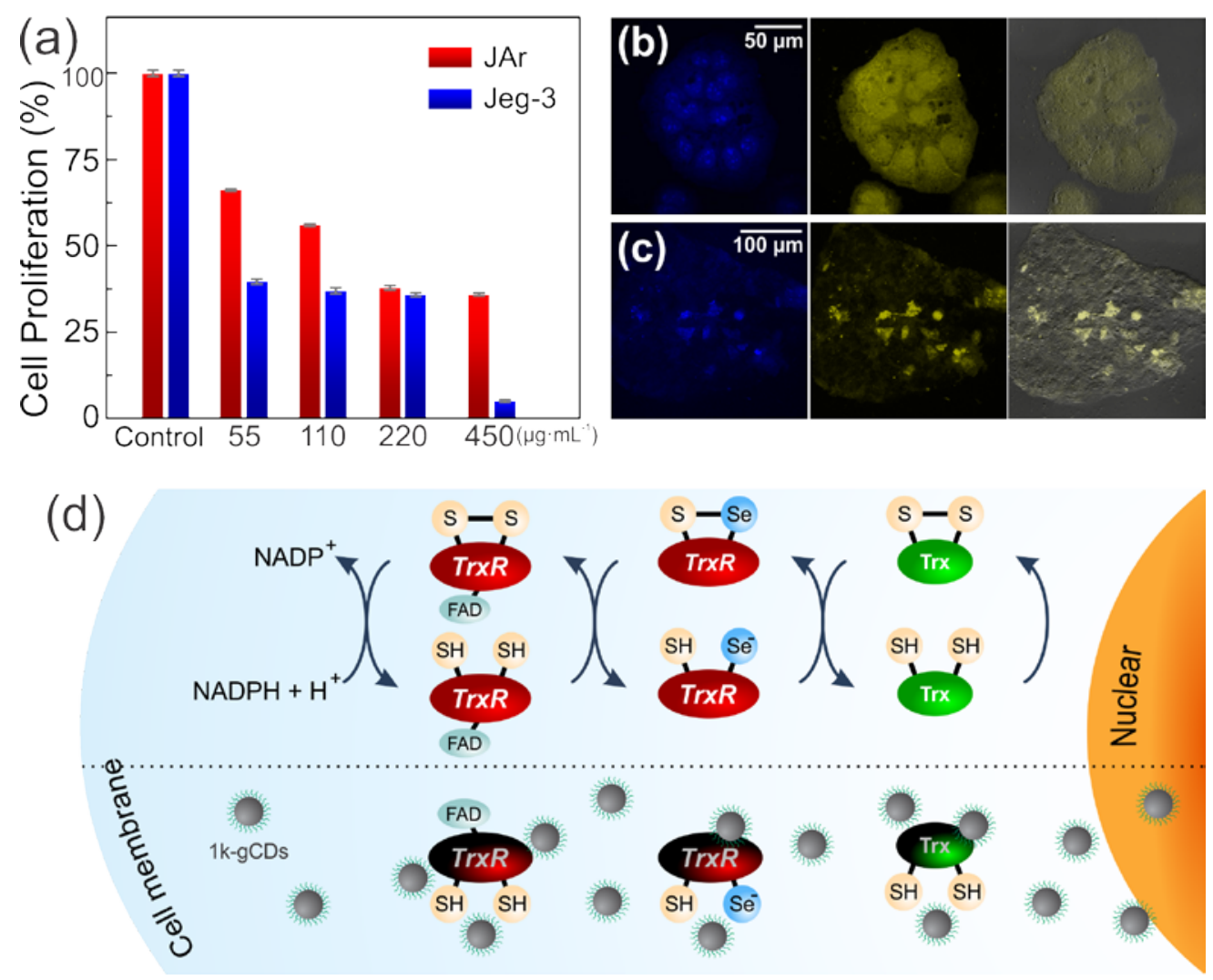

Figure 3(a). It is noteworthy that under the incubation times/conditions utilized in these assays the cells had not adhered to the base of the well prior to addition of the test CDs. It is possible that the $1 \mathrm{k}-\mathrm{gCD}$ may block processes associated with cell adherence and thus affect cellular proliferation. Several anticancer drugs are known to function by mechanisms which give similar effects[40]. These drugs are able to bind to tubulin monomers, blocking their polymerization[41]. This not only affects microtubule formation and thus cell division, but also affects cell adherence. Furthermore, nanoparticles including nanospheres, nanocapsules[42], and Au nanoparticles[43] have

Figure 3 (a) JAr and Jeg-3 proliferation assessed with 1k-gCDs introduced before cell adhesion ( $\left.\mu g \cdot \mathrm{mL}^{-1}\right)$, confocal images of a (b) $\mathrm{JAr}$ and (c) Jeg-3 cell incubated with $1 \mathrm{k}$-gCDs (from left: image captured at $\lambda_{\mathrm{Ex}}=405,473 \mathrm{~nm}$ and differential interference contrast image at $\lambda_{\mathrm{Ex}}=473 \mathrm{~nm}$ ). No noticeable fluorescence was detected from the control JAr and Jeg-3 cells (Figure S13). (d) schematic illustration of the Trx system (upper) and the Trx system with 1k-gCDs (lower).

demonstrated similar antiproliferative properties.

To further evaluate the antiproliferative efficacy of the $1 \mathrm{k}-\mathrm{gCDs}$, a dose response relationship was assessed across a range from 55 to $450 \mu \mathrm{g} \cdot \mathrm{mL}^{-1}$ (Figure 3 (a)). The $\mathrm{IC}_{50}$ values were determined to be 215.3 and $37.7 \mu \mathrm{g} \cdot \mathrm{mL}^{-1}$ for JAr and Jeg-3 cells respectively. Interestingly, under the incubation conditions resulting in non-adhered cells, $1 \mathrm{k}-\mathrm{gCDs}$ inhibited both JAr and Jeg-3 proliferation. Jeg-3 cells were more susceptible with subsequently lower $\mathrm{IC}_{50}$ values.

Jeg-3 cells produce higher levels of thioredoxin
(Trx)[17] and thus would be expected to be more resistant to oxidative toxins. However, cellular redox defences not only require Trx but also need a system of other proteins/enzymes to ensure that the Trx is in a reduced form, allowing it to overcome oxidative stress[18]. As presented in Figure 3 (d), the Trx system consists of a redox active protein (Trx, with two active cysteines), a homodimeric seleno-protein (thioredoxin reductase, $\operatorname{Tr} x \mathrm{R}$ ) and a nicotinamide adenine dinucleotide phosphate (NADPH). The Trx undergoes reversible oxidation forming a disulfide linkage. If one of the proteins (e.g. TrxR) is not present in high enough levels or TRx is not in a 

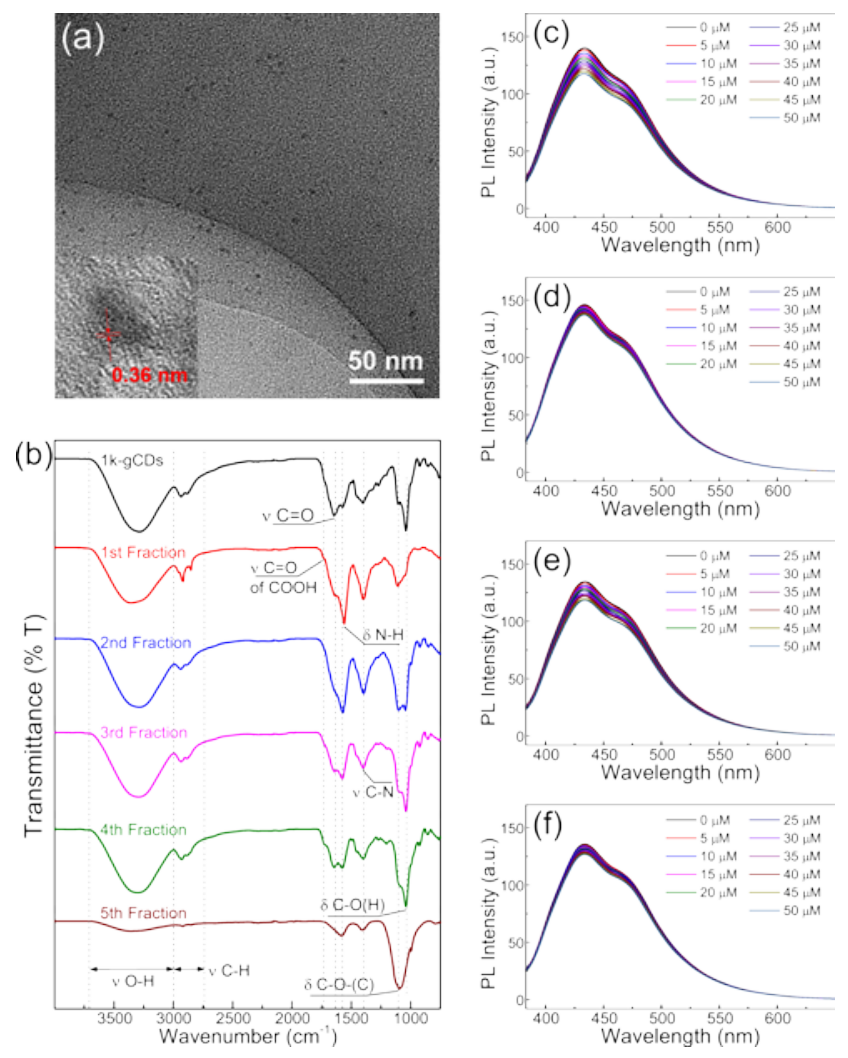

reduced state (e.g. $\left.\operatorname{Trx}-(\mathrm{SH})_{2}\right)$, there may be an accumulation of the oxidised form[44]. Consequently, despite having higher Trx levels, the redox state of the Jeg-3 cells may result in the Trx being present in an oxidized state (e.g. Trx-S $\mathrm{S}_{2}$ ). If so, this would push the cells towards oxidative stress and thus higher antiproliferative effects. The $1 \mathrm{k}-\mathrm{gCD}$ in the cells (Figure 3 (b) and (c)) presumably may interact with the reduced Trx or/and TrxR, similar to other systems reported previously[45-47]. Thus, the Trx system inhibition by the $1 \mathrm{k}-\mathrm{gCDs}$ may contribute to the greater antiproliferation affects, evident in the Jeg-3 cells. Further studies are ongoing to confirm if this is the case.

Figure 4 (a) TEM of $1 \mathrm{k}-\mathrm{gCDs}^{3 \mathrm{rd}}$, (b) IR spectra of the fractionated $1 \mathrm{k}$-gCDs by column chromatography, PL emission intensity responses of the $1 \mathrm{k}-\mathrm{CDs}$ against (c) cysteine, (d) sodium selenate, PL emission intensity responses of the $3^{\text {rd }}$ fraction of $1 \mathrm{k}$-gCDs against (d) cysteine, (e) sodium selenite (PL responses of the other fractions are presented in Supplementary Material).

\subsection{Further sample fractionation and surface functionality}

In order to evaluate the plausible interactions of the
1k-gCDs with Trx and/or TrxR, sulfur and selenium containing chemicals (cysteine and sodium selenate) were assessed by PL intensity responses of the $1 \mathrm{k}-\mathrm{gCDs}$. It is well recognized that PL emission properties of CDs are highly dependent on their surface states[5,16]. Thus, if these analytes are subject to binding onto the surface of the $1 \mathrm{k}-\mathrm{gCDs}$, changes in the PL emission would be expected. Preliminary results from the PL intensity response assessment of the $1 \mathrm{k}-\mathrm{gCDs}$ against cysteine and sodium selenate are presented in in Figure 4 (c) and (d). The PL intensity of the $1 \mathrm{k}-\mathrm{gCD}$ show consecutive decreases by adding increasing amounts of the analytes (cysteine and sodium selenate, any changes of PL intensities from sodium chloride was not observed (Figure S14)). This is highly likely due to the binding of the analytes onto the surface of the $1 \mathrm{k}-\mathrm{gCDs}$. However, no changes of PL emission intensities were observed from the $1 \mathrm{k}-\mathrm{wCDs}$ (figure $\mathrm{S14}$ ) which correlates well with no cell proliferative responses from the $1 \mathrm{k}-\mathrm{wCD}$.

In an attempt to describe the inhibition of Trx system by the $1 \mathrm{k}-\mathrm{gCDs}$ specific surface functionalities, we extended this PL assessment to further fractionated $1 \mathrm{k}$-gCDs. The $1 \mathrm{k}$-gCDs were fractionated into 5 different fractions by column chromatograph. Each fraction displayed different optical properties including notable changes in UV-Vis absorption peak at $\sim 340 \mathrm{~nm}$ and PL emission intensities (Figure S15).

Further TEM characterization reveal that the particles in the first $\left(1 \mathrm{k}-\mathrm{gCDs} \mathrm{s}^{1 \mathrm{st}}\right)$ and the fifth fraction $\left(1 \mathrm{k}-\mathrm{gCDs}^{5 \text { th }}\right)$ of the $1 \mathrm{k}-\mathrm{gCDs}$ are amorphous or oligomer/polymer based carbons since no particles could be detected via the TEM characterization[14,48]. However, the TEM from the third fraction $\left(1 \mathrm{k}-\mathrm{gCDs}{ }^{3 \mathrm{rd}}\right.$, Figure 7 (a)) shows that the particles are spherical with multiple carbon layers. Carbon lattices can also be observed which are separated at a distance of $\sim 0.36 \mathrm{~nm}$. These observations are identical to the TEM data from the unfractionated 1k-gCDs (Figure 1 (c)).

IR spectra of the fractionated 1k-gCDs in Figure 4 (b) further indicate that each fraction can be differentiated from each other. In contrast with the IR spectrum of the $1 \mathrm{k}-\mathrm{gCDs}$, the IR from the $1 \mathrm{k}-\mathrm{gCDs}{ }^{1 \mathrm{st}}$ 
shows a notably increased amount of amine (N-H bend, $1565 \mathrm{~cm}^{-1}$ ) and reduced hydroxyl (O-H bend, $\left.1035 \mathrm{~cm}^{-1}\right)$. The second fraction $\left(1 \mathrm{k}-\mathrm{gCDs}{ }^{2 n d}\right)$ shows a relatively higher amount of both amine and hydroxyl. Hydroxyls are dominant functional groups in the third and fourth fractions $\left(1 \mathrm{k}-\mathrm{gCDs}{ }^{3 \mathrm{rd}}\right.$ and $\left.1 \mathrm{k}-\mathrm{gCDs} \mathrm{s}^{4 \mathrm{th}}\right)$. Subsequently, the majority of the functional groups on the graphite/graphene-like carbon particles are hydroxyls with other groups including carboxyls and amines. It is also notable that the $1 \mathrm{k}-\mathrm{gCDs}^{5 \text { th }}$ contains a significantly reduced amount of functional groups. This may indicate that the particles in 1k-gCDs ${ }^{\text {th }}$ are not well functionalized. Accordingly, PL emission intensity of $1 \mathrm{k}-\mathrm{gCDs}^{5 \text { th }}$ is considerably decreased, in contrast with the other fractions.

The fractionated 1k-gCDs' PL responses against the analytes (cysteine, sodium selenite and sodium chloride) were further tested. As shown in Figure 7 and S16, the hydroxyl dominant $1 \mathrm{k}-\mathrm{gCDs}^{3 \mathrm{rd}}$ and $1 \mathrm{k}-\mathrm{gCD}^{4 \text { th }}$ display comparable PL intensity responses with the $1 \mathrm{k}-\mathrm{gCDs}$ (Figure 7 (c) and (d) vs. Figure 7 (e) and (f) / S16 (d)). The amine dominant $1 \mathrm{k}$-gCDs ${ }^{1 s t}$ and $1 \mathrm{~kg}-\mathrm{CDs}^{2 \mathrm{nd}}$ show no notable PL intensity changes, indicating no interaction between the analytes and the anime functionality/carbon core. Furthermore, no changes were also observed from the $1 \mathrm{k}-\mathrm{gCDs}^{5 \text { th }}$ which is likely due to the lack of the surface functional groups. These findings suggest that hydroxyls on the surface or the carbon core of the $1 \mathrm{k}$-gCDs may interact with sulfide and/or selenide in the Trx and/or TrxR, inhibiting the Trx system. The PL intensity responses may demonstrate a conceivable pathway of Trx system inhibition, although the analytes tested are not exactly identical to cysteine and selenocysteine in the Trx system. Further studies will be required in order to evaluate the precise mechanism of the antiproliferative activities from the $1 \mathrm{k}-\mathrm{gCDs}$.

\section{Conclusions}

In summary, we have synthesized a multivalent and hydroxyl-rich carbon dots, namely gCDs, by reacting citric acid and urea in glycerol under hydrothermal condition at $180^{\circ} \mathrm{C}$ for 24 hours. Glycerol is likely to be tethered on the CDs surface through esterification or hydrolamine formation. The enriched surface functionalities have an impact not only on the optical properties of the gCDs, namely exhibiting bright yellow emission, but also on the dots' interactions with biological entities.

Our finding suggest that the CD samples displayed different toxic responses depending on the biological entities tested. In our comparative study using the pair of $\mathrm{g}-\mathrm{CDs}$ and $\mathrm{wCDs}$, since the particle sizes are comparable between the samples, the surface functional groups of the $\mathrm{CDs}$ are likely to be responsible for the various toxicity results. The $1 \mathrm{k}-w C D s^{\prime}$ toxic effects against Petunia axillaris seedlings and A. franciscana nauplii may originate from carboxyl and amine surface functionalities. In contrast, the gCDs, which are predominantly covered with hydroxyls derived from glycerol, displayed very good biocompatibilities throughout the biological entities tested in this study.

Moreover, the variations in the application of gCDs in cell culture demonstrated that $1 \mathrm{k}$-gCDs possess antiproliferative properties, potentially affecting cell adhesion. The antiproliferation activities were higher toward Jeg-3 choriocarcinoma cells in comparison to JAr, whereas Jeg-3 produces much higher amount of Trx. We further demonstrated that the combined effect of hydroxyl functional groups and the particle size $(1-2 \mathrm{~nm})$ of the $1 \mathrm{k}-\mathrm{gCD}$ may be responsible for the substantial antiproliferative activities of Jeg-3 via Trx system inhibition. Such an effect may be further explored for cancer drug discovery.

\section{Experimental Section}

Sample synthesis and fractionation: All the chemicals used for the sample preparation were purchased from Chem-Supply Pty Ltd, Australia and used as received. Synthesis of the samples was carried out in a 30mL PTFE-lined autoclave. Masses of $0.5 \mathrm{~g}$ of urea and $0.16 \mathrm{~g}$ of citric acid were mixed (10:1 molar ration) in either glycerol or water (10 $\mathrm{mL}$ ) and placed in the autoclave. The autoclave was sealed and maintained at $180^{\circ} \mathrm{C}$ for 24 hours and then the autoclave was cooled to room temperature 
and samples were collected for further processing. Dialysis membranes were acquired from Spectrum Laboratories, Inc. Dialysis was performed twice at different molecular weight cut-offs (MWCOs) for obtaining pure and mono-dispersed CD samples. Prior to dialysis, all the samples were filtered through $0.22 \mu \mathrm{m}$ syringe filters in order to remove large aggregates. The filtrate was subsequently placed in a $3.5 \mathrm{kDa}$ membrane bag (the volume of each dialysis bag was prepared at $80 \mathrm{~mL}$ ) and dialyzed against large amount of water $(20 \mathrm{~mL}$ of sample solution/6L of water for 36 hours, $500 \mathrm{~mL}$ of water was added every 2 hours and left for 12 hours further). The sample collected in the $3.5 \mathrm{KDa}$ membrane bag was named $3.5 \mathrm{kCDs}$. The sample out of the $3.5 \mathrm{kDa}$ bag was condensed in a rotary evaporator and the condensed sample was placed in a $1 \mathrm{kDa}$ membrane bag for further dialysis. The sample collected in the $1 \mathrm{kDa}$ bag was named $1 \mathrm{k}$-CDs. 1k-gCDs were further fractionated by a silica gel filled column and methanol was used as an eluent. The methanol in the fractionated $1 \mathrm{k}-\mathrm{gCD}$ was evaporated by a rotavap.

Artemia franciscana nauplii toxicity screening: The Artemia franciscana nauplii (brine shrimp larvae) lethality bioassay was employed to examine the toxicity of CDs. Artemia franciscana cysts were obtained from North American Brine Shrimp, LLC, USA (harvested from the Great Salt Lake, Utah). The cysts were hatched in synthetic seawater and the nauplii were separated from the shells and used for the test. A volume of $400 \mu \mathrm{L}$ of seawater containing approximately $50 \mathrm{~A}$. franciscana nauplii were added to wells of a 48-well plate and immediately used for bioassay. A volume of $400 \mu \mathrm{L}$ of samples or a reference toxin $\left(1 \mathrm{mg} \cdot \mathrm{mL}^{-1}\right.$, potassium dichromate, Chem-Supply, Australia) were transferred to the wells and incubated at $25^{\circ} \mathrm{C}$ under artificial light (1000 Lux). A negative control ( $400 \mu \mathrm{L}$ seawater) was run in triplicate for each plate. All treatments were performed in triplicate. The wells were checked at regular intervals and the number of dead counted. The nauplii were considered dead if no movement of the appendages was observed within 10 seconds. After 48 hours all nauplii were sacrificed by adding $100 \mu \mathrm{L}$ of acetic acid (concentrated, Chem-Supply, Australia) to each well and counted to facilitate the total \% mortality per well.

Plant toxicity: The tests were performed using commercially available Petunia axillaris seedlings from a local nursery which were grown hydroponically. In order to feed CD samples directly to the seedlings, the soils on their root were washed and placed in flasks with cotton wool. A $3 \mathrm{~mL}$ volume of the CD samples (concentration $200 \mu \mathrm{g} \cdot \mathrm{mL}-1$ ) were fed every 2 days for 4 weeks in a controlled environment. The sample infiltration tests were performed by infiltrating $0.5 \mathrm{~mL}$ of the $\mathrm{CD}$ samples at a concentration of $200 \mu \mathrm{g} \cdot \mathrm{mL}^{-1}$ by $1 \mathrm{~mL}$ syringes without needles on the back of the target leaves.

Evaluation of antimicrobial activity: Antimicrobial activity of all plant extracts was determined using a disc diffusion assay. Briefly, $100 \mu \mathrm{L}$ of the test bacteria were grown in $10 \mathrm{~mL}$ of fresh nutrient broth media until they reached a count of approximately 108 cells $\cdot \mathrm{mL}^{-1}$. An amount of $100 \mu \mathrm{L}$ of bacterial suspension was spread onto nutrient agar plates. The CDs were tested for antibacterial activity using $5 \mathrm{~mm}$ sterilised filter paper discs. Discs were impregnated with $10 \mu \mathrm{L}$ of the test sample, allowed to dry and placed onto inoculated plates. The plates were allowed to stand at $4^{\circ} \mathrm{C}$ for 2 hours before incubation with the test CDs. Plates were incubated at $30^{\circ} \mathrm{C}$ for 24 hours, then the diameters of the inhibition zones were measured in millimetres. All measurements were to the closest whole millimetre. Each antimicrobial assay was performed in at least triplicate. Standard discs of ampicillin $(2 \mu \mathrm{g})$ and chloramphenicol $(10 \mu \mathrm{g})$ were obtained from Oxoid Ltd. and served as positive controls for antibacterial activity. Filter discs impregnated with $10 \mu \mathrm{L}$ of distilled water were used as a negative control.

Cell lines: Tongue Squamous (CAL27) carcinoma cell line was obtained from School of Life Science, Sun Yat-sen University (Guangzhou, China). Human breast (MCF7) carcinoma cell line and Human Embryonic Kidney (HEK293) cell line were donated by QIMR Berghofer Medical Research Institute (Brisbane, QLD). All the adherent cell lines were maintained in Dulbecco's Modified Eagle Medium/Nutrient Mixture F-12 (DMEM/F12 medium, Life technologies) supplemented with $10 \%$ 
foetal bovine serum (FBS) at $37^{\circ} \mathrm{C}$ in a humidified atmosphere with $5 \% \mathrm{CO}_{2}$ in air. JAr and Jeg-3 choriocarcinoma cell lines used in this study were obtained from American Type Culture Collection (Rockville, USA). The cells were cultured in Roswell Park Memorial Institute (RPMI) 1640 medium (Life Technologies), supplemented with 20 mM HEPES, 10 $\mathrm{mM}$ sodium bicarbonate, $50 \mu \mathrm{g} \cdot \mathrm{mL}-1$ streptomycin, $50 \mathrm{IU} \cdot \mathrm{mL}-1$ penicillin, $2 \mathrm{mM}$ glutamine and $10 \%$ fetal calf serum (Life Technologies). The cells were maintained as monolayers in $75 \mathrm{ml}$ flasks at $37^{\circ} \mathrm{C}$, $5 \% \mathrm{CO}_{2}$ in a humidified atmosphere until approximately $80 \%$ confluent.

HEK293, CAL27 and MCF7 Cell viability/inhibition assay: Cells at $70-80 \%$ confluency were harvested and plated with optimal cell density in the 384-well microplate and incubated at $37^{\circ} \mathrm{C}, 5 \% \mathrm{CO}_{2}$ overnight. The cells were treated with the sample CDs and were incubated for $24 \mathrm{~h}$ at $37^{\circ} \mathrm{C}$ in $5 \% \mathrm{CO}_{2}$. A $5 \mu \mathrm{L}$ volume of alamarBlue (Thermo Scientific) were added in the wells after the incubation. The plate was read using a Biotek Synergy 2 multi-mode microplate reader with excitation of $560 \mathrm{~nm}$ and emission of $590 \mathrm{~nm}$ after 24 h. A medium without cells was set as the blank control whilst $0.5 \%$ DMSO served as the vehicle control. The cell inhibition was expressed as fluorescence intensity in the presence of the test CDs as a percentage of that in the vehicle control using the following formula (Equation 1):

Cell inhibition $(g)=100-\frac{F_{E_{\mathrm{Ep}}}-F_{\mathrm{BC}}}{F_{\mathrm{WC}}-F_{\mathrm{BC}}} \times 100$

Equation 1

$F_{E x p}$ is the fluorescence intensity of the test CDs, $F_{B C}$ is the fluorescence intensity of the blank control $F_{V C}$ is the fluorescence intensity of the vehicle control. All the experiments were performed in biological triplicates.

Jeg-3 and JAr Cell proliferation test: A $1 \mathrm{ml}$ volume of trypsin (Sigma) was added to the culture flasks and incubated at $37^{\circ} \mathrm{C}, 5 \% \mathrm{CO}_{2}$ for $15 \mathrm{~min}$ to dislodge the cells. The cell suspensions were then transferred to a $10 \mathrm{~mL}$ centrifuge tube and sedimented by centrifugation. The supernatant was discarded and the cells were resuspended in $9 \mathrm{~mL}$ of fresh media. Aliquots of the resuspended cells $(70 \mu \mathrm{L}$, containing approximately 5000 cells) were added to the wells of a 96 well plate. A volume of $30 \mu \mathrm{L}$ of the test CDs or cell media (for the negative control) was added to individual wells and the plates were incubated at $37^{\circ} \mathrm{C}, 5 \% \mathrm{CO}_{2}$ for 24 hours in a humidified atmosphere. A volume of $20 \mu \mathrm{L}$ of Cell Titre 96 Aqueous One solution (Promega) was subsequently added to each well and the plates were incubated for further 24 hours. Absorbances were recorded at $490 \mathrm{~nm}$ using a Molecular Devices, Spectra Max M3 plate reader. All tests were performed in at least triplicate and triplicate controls were included on each plate. The antiproliferative activity of each test was calculated as a percentage of the negative control using the following formula (Equation 2):

Cell Proliferation $(\phi)=\frac{A_{z z}}{A_{z z}} \times 100$

Equation 2

$A_{c t}$ is the corrected absorbance for the test $\mathrm{CD}$ solution (calculated by subtracting the absorbance of the test $\mathrm{CD}$ solution in media without cells from the extract cell test combination) and $A_{c c}$ is the corrected untreated control (calculated by subtracting the absorbance of the untreated control in media without cells from the untreated cell media combination). IC50 values were calculated using OriginPro 9.0.0 software packages.

1k-gCDs photoluminescence quenching test: $1 \mathrm{~mL}$ of $1 \mathrm{k}$-gCDs or fractionated $1 \mathrm{k}$-gCDs were mixed with $1 \mathrm{~mL}$ of analyte solutions (cysteine, sodium selenate and sodium chloride) prepared at 5 to $50 \mu \mathrm{M}$. PL intensity responses were measured by fluorescent spectrometer. Cysteine and sodium chloride were purchased from Chem-Supply, Australia and sodium selenate was acquired from Sigma-Aldrich. The chemicals were used without further purification.

Sample characterization: Atomic force microscopy (AFM) images were captured on a NT-MDT NTEGRA Spectra AFM by semi-contact mode. Hydrodynamic particle size and zeta potential were measured on a Malvern Zetasizer Nano ZS using dynamic light scattering (DLS) technique. High 
resolution transmission electron microscopy images were acquired from a FEI Titan G2 80-200 at 100kV. Fourier transform infrared (FTIR) spectra were recorded on a Perkin Elmer Spectrum Two FTIR spectrometer using an attenuated total reflection (ATR) attachment and a baseline correction was applied after the measurement. X-ray photoelectron spectroscopy (XPS) spectra were acquired using a Kratos Axis ULTRA X-ray photoelectron spectrometer incorporating a $165 \mathrm{~mm}$ hemispherical electron energy analyser. Atomic concentration and peak fittings were carried out using a CasaXPS version 2.2.73 software packages. Raman spectra were recorded on a Reinshaw InVia using $514 \mathrm{~nm}$ excitation and a baseline correction was applied. Fluorescence emission spectra were recorded on a Thermo Scientific Lumina fluorescence spectrometer and UV visible (UV-vis) absorption spectra were measured in an Agilent $8453 \mathrm{UV}$-vis spectrometer. Quantum yields (QY) were calculated by comparing the integrated photoluminescence intensity values and the absorption values with a reference sample. Fluorescence microscopy images of A. franciscana nauplii were captured on an Olympus IX70 epifluorescence microscope at the excitation of 405 and $488 \mathrm{~nm}$ and the exposure time for each excitation was 450 and $1500 \mathrm{~ms}$ respectively. Laser scanning confocal microscope fluorescent and differential contrast images were taken using an Olympus FV1000 microscope and processed on FV10-ASW 3.01.01.09 Viewer software packages. In order to enhance presentation, brightness and contrast were adjusted uniformly across the field of view using the FV10-ASW 3.1 Viewer software and ImageJ $1.47 \mathrm{t}$ software packages.

\section{Acknowledgements}

T. K. acknowledges the support of Australian Postgraduate Award and Queensland Smart Futures PhD Scholarship. Q.L. acknowledges Griffith University Research Infrastructure Funding and Griffith School of Engineering Research Seed Funding. The authors acknowledge Dr Barry Wood at the University of Queensland for his assistance in
XPS analyses, Dr Fatima Naim at Queensland University of Technology for her assistance in plant toxicity assessments, and Dr. Giovanna Di Trapani for discussions on the TRx system.

Electronic Supplementary Material: Physiochemical and Optical properties of wCDs, Toxicity results of gCDs and wCDs, Confocal images of reference JAr and Jeg-3 cell, optical properties and PL responses of the column fractionated $1 \mathrm{k}-\mathrm{gCD}$ are available in the online version of this article at http://dx.doi.org/10.1007/s12274-*******_*

\section{References}

[1] Prasad, P. N. Introduction to Nanomedicine and Nanobioengineering; John Wiley \& Sons, 2012.

[2] Baker, S. N.; Baker, G. A. Luminescent Carbon Nanodots: Emergent Nanolights. Angew. Chemie Int. Ed. 2010, 49, 6726-6744.

[3] Li, Q.; Ohulchanskyy, T. Y.; Liu, R.; Koynov, K.; Wu, D.; Best, A.; Kumar, R.; Bonoiu, A.; Prasad, P. N. Photoluminescent Carbon Dots as Biocompatible Nanoprobes for Targeting Cancer Cells in Vitro. J. Phys. Chem. C 2009, 114, 4598-4601.

[4] Zhu, S.; Meng, Q.; Wang, L.; Zhang, J.; Song, Y.; Jin, H.; Zhang, K.; Sun, H.; Wang, H.; Yang, B. Highly Photoluminescent Carbon Dots for Multicolor Patterning, Sensors, and Bioimaging. Angew. Chemie Int. Ed. 2013, 52, 3953-3957.

[5] Nie, H.; Li, M.; Li, Q.; Liang, S.; Tan, Y.; Sheng, L.; Shi, W.; Zhang, S. X-A. Carbon Dots with Continuously Tunable Full-Colour Emission and Their Application in Ratiometric pH Sensing. Chem. Mater. 2014, 26, 3104-3112.

[6] Kim, T. H.; Wang, F.; McCormick, P.; Wang, L.; Brown, C.; Li, Q. Salt-Embedded Carbon Nanodots as a UV and Thermal Stable Fluorophore for Light-Emitting Diodes. $J$. Lumin. 2014, 154, 1-7.

[7] Kim, T. H.; White, A. R.; Sirdaarta, J. P.; Ji, W.; Cock, I. E.; St. John, J.; Boyd, S. E.; Brown, C. L.; Li, Q. Yellow-Emitting Carbon Nanodots and Their Flexible and Transparent Films for White LEDs. ACS Appl. Mater. Interfaces 2016, 8, 33102-33111.

[8] Hong, G.; Diao, S.; Antaris, A. L.; Dai, H. Carbon Nanomaterials for Biological Imaging and Nanomedicinal Therapy. Chem. Rev. 2015, 115, 10816-10906.

[9] Zeng, Q.; Shao, D.; He, X.; Ren, Z.; Ji, W.; Shan, C.; Qu, S.; Li, J.; Chen, L.; Li, Q. Carbon Dots as a Trackable Drug Delivery Carrier for Localized Cancer Therapy in 
Vivo. J. Mater. Chem. B 2016, 4, 5119-5126.

[10] Cao, L.; Meziani, M. J.; Sahu, S.; Sun, Y. P. Photoluminescence Properties of Graphene versus Other Carbon Nanomaterials. Acc. Chem. Res. 2013, 46, 171-180.

[11] Zhu, H.; Wang, X.; Li, Y.; Wang, Z.; Yang, F.; Yang, X. Microwave Synthesis of Fluorescent Carbon Nanoparticles with Electrochemiluminescence Properties. Chem. Commun. 2009, 34, 5118-5120.

[12] Wang, F.; Pang, S. P.; Wang, L.; Li, Q.; Kreiter, M.; Liu, C. Y. One-Step Synthesis of Highly Luminescent Carbon Dots in Noncoordinating Solvents. Chem. Mater. 2010, 22, 4528-4530.

[13] Ding, H.; Yu, S. B.; Wei, J. S.; Xiong, H. M. Full-Color Light-Emitting Carbon Dots with a Surface-State-Controlled Luminescence Mechanism. ACS Nano 2016, 10, 484-491.

[14] Strauss, V.; Margraf, J. T.; Dolle, C.; Butz, B.; Nacken, T. J.; Walter, J.; Bauer, W.; Peukert, W.; Spiecker, E.; Clark, T.; Guldi, D. M. Carbon Nanodots: Toward a Comprehensive Understanding of Their Photoluminescence. J. Am. Chem. Soc. 2014, 136, 17308-17316.

[15] Zhu, S.; Zhang, J.; Tang, S.; Qiao, C.; Wang, L.; Wang, H. Surface Chemistry Routes to Modulate the Photoluminescence of Graphene Quantum Dots: From Fluorescence Mechanism to Up-Conversion Bioimaging Applications. Adv. Funct. Mater. 2012, 22, 4732-4740.

[16] Kim, T. H.; Ho, H. W.; Brown, C. L.; Cresswell, S. L.; Li, Q. Amine-Rich Carbon Nanodots as a Fluorescence Probe for Methamphetamine Precursors. Anal. Methods 2015, 7, 6869-6876.

[17] Di Trapani, G.; Perkins, A.; Clarke, F. Production and Secretion of Thioredoxin from Transformed Human Trophoblast Cells. Mol. Hum. Reprod. 1998, 4, 369-375.

[18] Toyo, S. Persistent Oxidative Stress in Cancer Antioxidant T Damage Oncogene. FEBS Lett. 1995, 358, $1-3$.

[19] Tang, L.; Ji, R.; Li, X.; Bai, G.; Liu, C. P.; Hao, J.; Lin, J.; Jiang, H.; Teng, K. S.; Yang, Z.; Lau, S. P. Deep Ultraviolet to near-Infrared Emission and Photoresponse in Layered N-Doped Graphene Quantum Dots. ACS Nano 2014, 8, 6312-6320.

[20] Titirici, M.-M. M.; Antonietti, M. Chemistry and Materials Options of Sustainable Carbon Materials Made by Hydrothermal Carbonization. Chem. Soc. Rev. 2010, 39, 103-116.

[21] Li, X.; Zhang, S.; Kulinich, S. a; Liu, Y.; Zeng, H. Engineering Surface States of Carbon Dots to Achieve Controllable Luminescence for Solid-Luminescent Composites and Sensitive Be2+ Detection. Sci. Rep. 2014, 4, 4976.

[22] Nimlos, M. R.; Blanksby, S. J.; Qian, X.; Himmel, M. E.; Johnson, D. K. Mechanisms of Glycerol Dehydration. $J$.
Phys. Chem. A 2006, 110, 6145-6156.

[23] Bühler, W.; Dinjus, E.; Ederer, H. J.; Kruse, A.; Mas, C. Ionic Reactions and Pyrolysis of Glycerol as Competing Reaction Pathways in near- and Supercritical Water. $J$. Supercrit. Fluids 2002, 22, 37-53.

[24] Krysmann, M. J.; Kelarakis, A.; Dallas, P.; Giannelis, E. P. Formation Mechanism of Carbogenic Nanoparticles with Dual Photoluminescence Emission. J. Am. Chem. Soc. 2012, 134, 747-750.

[25] Ferrari, A. C.; Meyer, J. C.; Scardaci, V.; Casiraghi, C.; Lazzeri, M.; Mauri, F.; Piscanec, S.; Jiang, D.; Novoselov, K. S.; Roth, S.; et al. Raman Spectrum of Graphene and Graphene Layers. Phys. Rev. Lett. 2006, 97, 187401.

[26] Amarnath, C. A.; Hong, C. E.; Kim, N. H.; Ku, B.-C. C.; Kuila, T.; Lee, J. H. Efficient Synthesis of Graphene Sheets Using Pyrrole as a Reducing Agent. Carbon 2011, 49, 3497-3502.

[27] Chang, P. R.; Jian, R.; Zheng, P.; Yu, J.; Ma, X. Preparation and Properties of Glycerol Plasticized-Starch (GPS)/cellulose Nanoparticle (CN) Composites. Carbohydr. Polym. 2010, 79, 301-305.

[28] Williams, D. H.; Fleming, I. Spectroscopic Methods in Organic Chemistry; McGraw-Hill Higher Education: New York; Maidenhead, 2008.

[29] Unni, S. M.; Devulapally, S.; Karjule, N.; Kurungot, S. Graphene Enriched with Pyrrolic Coordination of the Doped Nitrogen as an Efficient Metal-Free Electrocatalyst for Oxygen Reduction. J. Mater. Chem. 2012, 22, 23506-23513.

[30] Pels, J. R.; Kapteijn, F.; Moulijn, J. A.; Zhu, Q.; Thomas, K. M. Evolution of Nitrogen Functionalities in Carbonaceous Materials during Pyrolysis. Carbon 1995, 33, 1641-1653.

[31] Tian, F.; Cui, Y.; Teplyakov, A. V. Nitroxidation of H-Terminated Si(111) Surfaces with Nitrobenzene and Nitrosobenzene. J. Phys. Chem. C 2014, 118, 502-512.

[32] Hammond, C.; Lopez-Sanchez, J. A.; Hasbi Ab Rahim, M.; Dimitratos, N.; Jenkins, R. L.; Carley, A. F.; He, Q.; Kiely, C. J.; Knight, D. W.; Hutchings, G. J. Synthesis of Glycerol Carbonate from Glycerol and Urea with Gold-Based Catalysts. Dalt. Trans. 2011, 40, 3927-3937.

[33] Seredycha, M.; Hulicova-Jurcakovab D.; Lu G.; Bandosz T. Surface Functional Groups of Carbons and the Effects of Their Chemical Character, Density and Accessibility to Ions on Electrochemical Performance. Carbon 2008, 46, 1475-1488.

[34] Lin, Z.; Waller, G.; Liu, Y.; Liu, M.; Wong, C.-P. Facile Synthesis of Nitrogen-Doped Graphene via Pyrolysis of Graphene Oxide and Urea, and Its Electrocatalytic Activity toward the Oxygen-Reduction Reaction. Adv. Energy Mater. 2012, 2, 884-888.

[35] Dong, F.; Wu, L.; Sun, Y.; Fu, M.; Wu, Z.; Lee, S. C. Efficient Synthesis of Polymeric G-C3N4 Layered Materials as Novel Efficient Visible Light Driven 
Photocatalysts. J. Mater. Chem. 2011, 21, 15171-15174.

[36] Bhunia, S. K.; Saha, A.; Maity, A. R.; Ray, S. C.; Jana, N. R. Carbon Nanoparticle-Based Fluorescent Bioimaging Probes. Sci. Rep. 2013, 3, 1473.

[37] Ruebhart, D. R.; Wickramasinghe, W.; Cock, I. E. Protective Efficacy of the Antioxidants Vitamin E and Trolox against Microcystis Aeruginosa and Microcystin-LR in Artemia Franciscana Nauplii. J. Toxicol. Environ. Health. A 2009, 72, 1567-1575.

[38] Naim, F.; Nakasugi, K.; Crowhurst, R. N.; Hilario, E.; Zwart, A. B.; Hellens, R. P.; Taylor, J. M.; Waterhouse, P. M.; Wood, C. C. Advanced Engineering of Lipid Metabolism in Nicotiana Benthamiana Using a Draft Genome and the V2 Viral Silencing-Suppressor Protein. PLoS One 2012, 7, e52717.

[39] Leroueil, P. R.; Hong, S.; Mecke, A.; Baker, J. R.; Orr, B. G.; Holl, M. M. B. Nanoparticle Interaction with Biological Membranes: Does Nanotechnology Present a Janus Face? Acc. Chem. Res. 2007, 40, 335-342.

[40] Thun, M. J.; Henley, S. J.; Patrono, C. Nonsteroidal Anti-Inflammatory Drugs as Anticancer Agents: Mechanistic, Pharmacologic, and Clinical Issues. J. Natl. Cancer Inst. 2002, 94, 252-266.

[41] Brancale, A.; Silvestri, R. Indole, a Core Nucleus for Potent Inhibitors of Tubulin Polymerization. Med. Res. Rev. 2007, 27, 209-238.

[42] Brigger, I.; Dubernet, C.; Couvreur, P. Nanoparticles in
Cancer Therapy and Diagnosis. Adv. Drug Deliv. Rev. 2012, 64, 24-36.

[43] Fratoddi, I.; Venditti, I.; Cametti, C.; Russo, M. V. How Toxic Are Gold Nanoparticles? The State-of-the-Art. Nano Res. 2015, 8, 1771-1799.

[44] Urig, S.; Becker, K. On the Potential of Thioredoxin Reductase Inhibitors for Cancer Therapy. Semin. Cancer Biol. 2006, 16, 452-465.

[45] Gromer, S.; Arscott, L. D.; Williams, C. H.; Schirmer, R. H.; Becker, K. Human Placenta Thioredoxin Reductase. Isolation of the Selenoenzyme, Steady State Kinetics, and Inhibition by Therapeutic Gold Compounds. J. Biol. Chem. 1998, 273, 20096-20101.

[46] Fang, J.; Holmgren, A. Inhibition of Thioredoxin and Thioredoxin Reductase by 4-Hydroxy-2-Nonenal in Vitro and in Vivo. J. Am. Chem. Soc. 2006, 128, 1879-1885.

[47] Srivastava, M.; Singh, S.; Self, W. T. Exposure to Silver Nanoparticles Inhibits Selenoprotein Synthesis and the Activity of Thioredoxin Reductase. Environ. Health Perspect. 2012, 120, 56-61.

[48] Fu, M.; Ehrat, F.; Wang, Y.; Milowska, K. Z.; Reckmeier, C.; Rogach, A. L.; Stolarczyk, J. K.; Urban, A. S.; Feldmann, J. Carbon Dots: A Unique Fluorescent Cocktail of Polycyclic Aromatic Hydrocarbons. Nano Lett. 2015, 15, 6030-6035. 


\section{Electronic Supplementary Material}

\section{Selective Toxicity of Hydroxyl-Rich Carbon Nanodots for Cancer Research}

Tak H. Kim ${ }^{1}$, Joseph P. Sirdaarta ${ }^{2}$, Qian Zhang ${ }^{3}$, Ehsan Eftekhari ${ }^{1}$, James St. John ${ }^{3,4}$, Derek Kennedy ${ }^{3}$, Ian E. $\operatorname{Cock}^{2}$, and Qin $\operatorname{Li}^{1}(\bowtie)$

Type author addresses here. The font is Times New Roman 9. The affiliation should be the institution where the work was conducted. If the present address of an author differs from that at which the work was carried out, please give the present address as well. For example,

${ }^{1}$ Queensland Micro and Nano Technology Center \& School of Engineering, Griffith University, 170 Kessels Rd, Nathan QLD 4111, Australia

${ }^{2}$ Australian Rivers Institute \& School of Natural Sciences, Griffith University, 170 Kessels Rd, Nathan QLD 4111, Australia

${ }^{3}$ Griffith Institute for Drug Discovery, Griffith University, 46 Don Young Rd, Nathan QLD 4111, Australia

${ }^{4}$ Menzies Health Institute Queensland, Griffith University, Parkland Drive, Southport QLD 4222, Australia

Supporting information to DOI $10.1007 /$ s12274-****_****_* (automatically inserted by the publisher) 


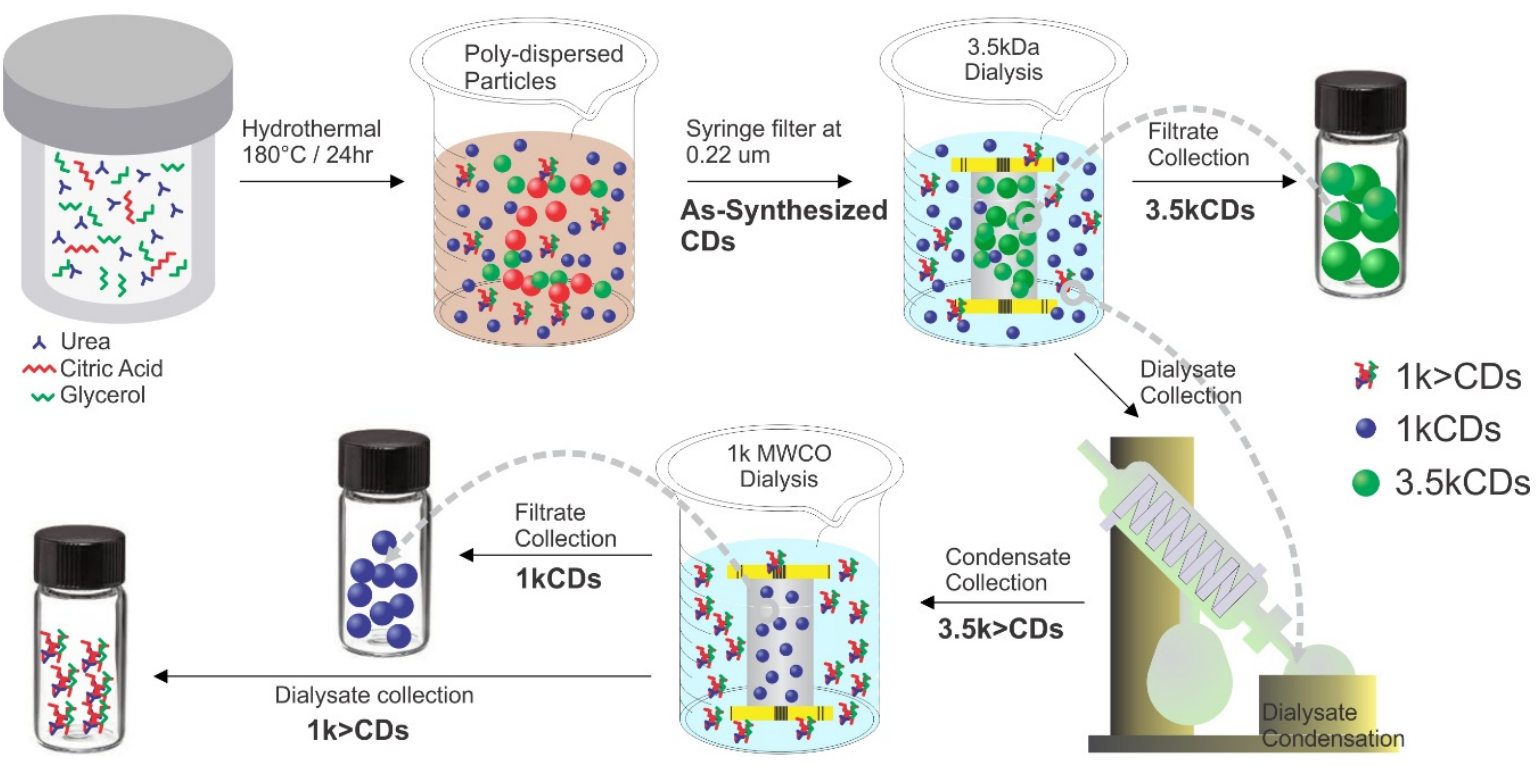

Scheme S1 Sample synthesis and the fractionation process.
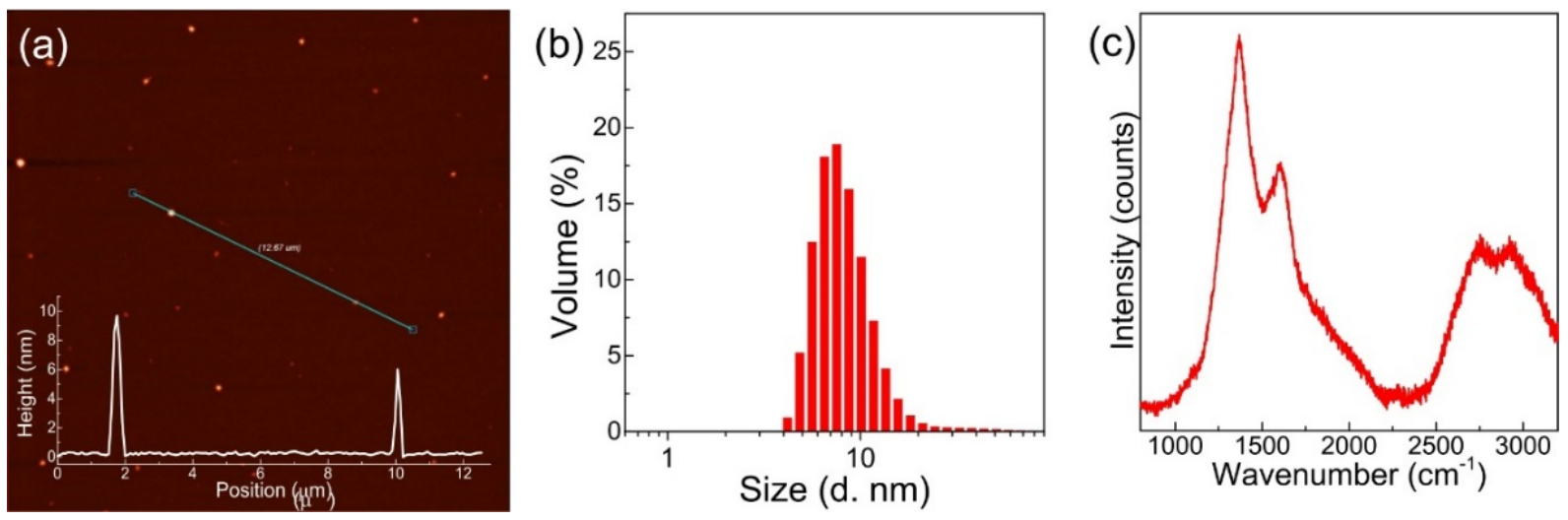

Figure S1 (a) AFM, (b) DLS and (c) Raman spectrum of 3.5k-gCDs. 

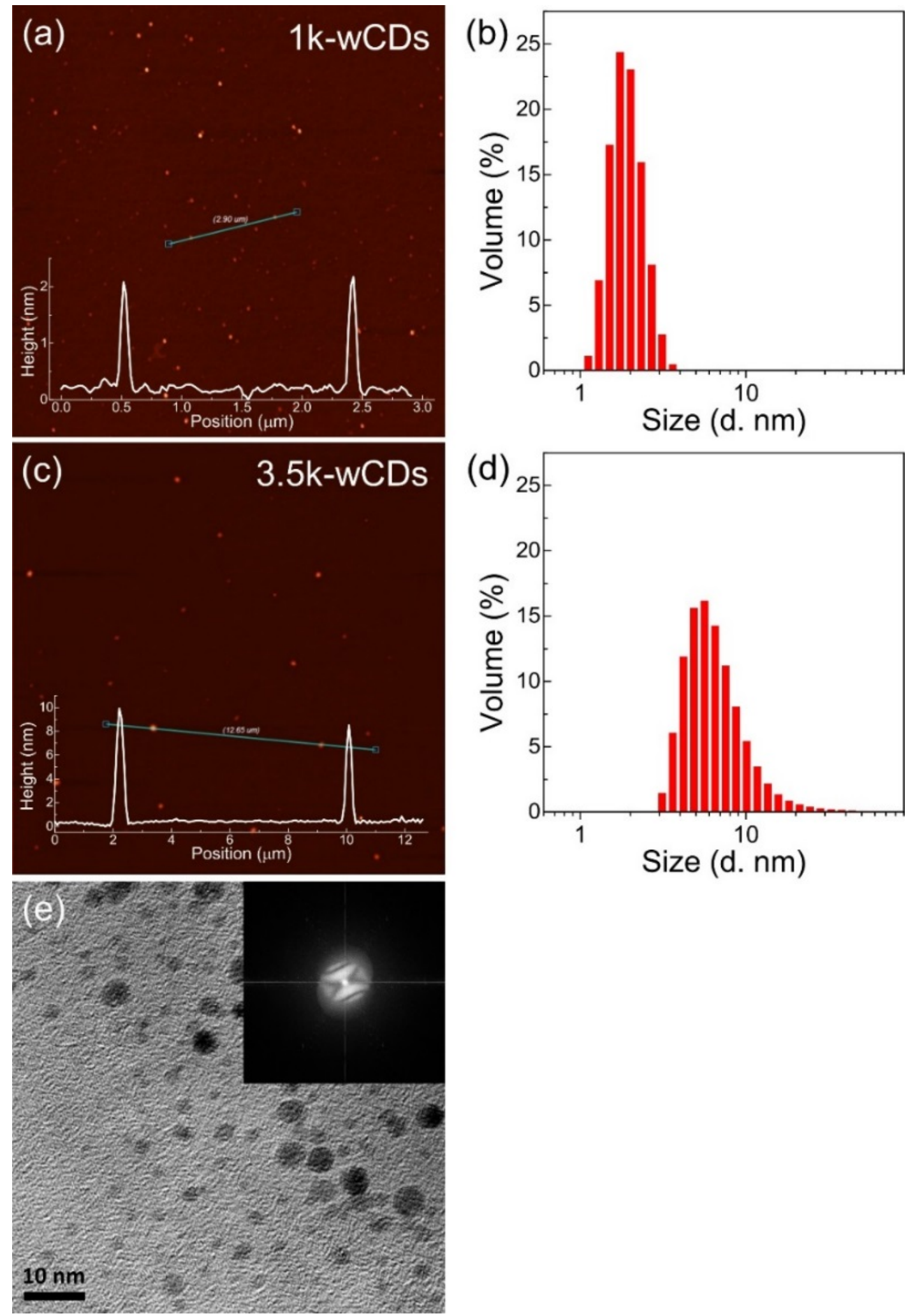

Figure S2 (a) AFM, (b) DLS of 1k-wCDs, (c) AFM, (d) DLS of 3.5k-wCDs and (e) HRTEM of 1k-wCDs. 

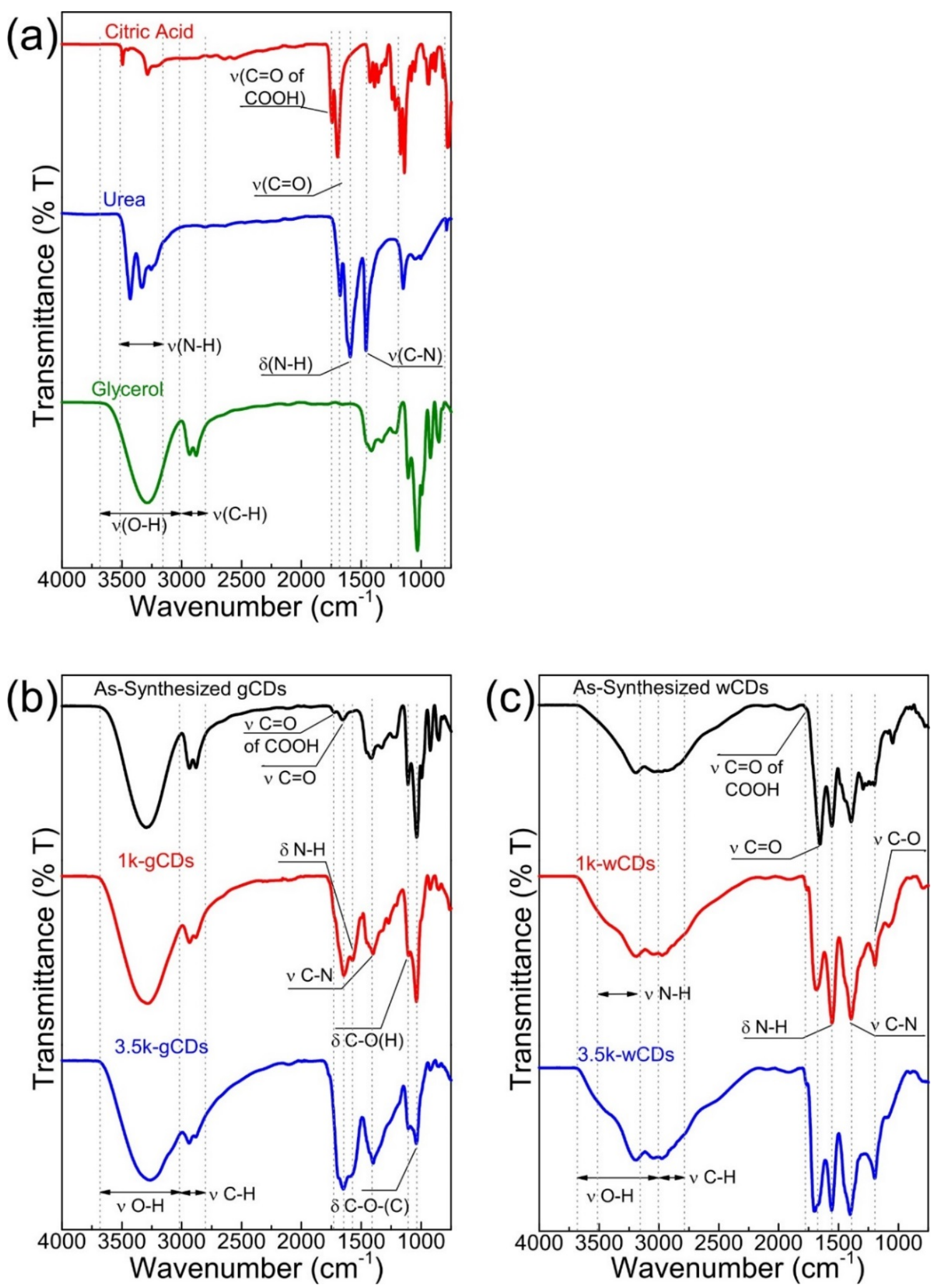

Figure S3 IR spectra of (a) starting materials (b) gCDs and (c) wCDs. 

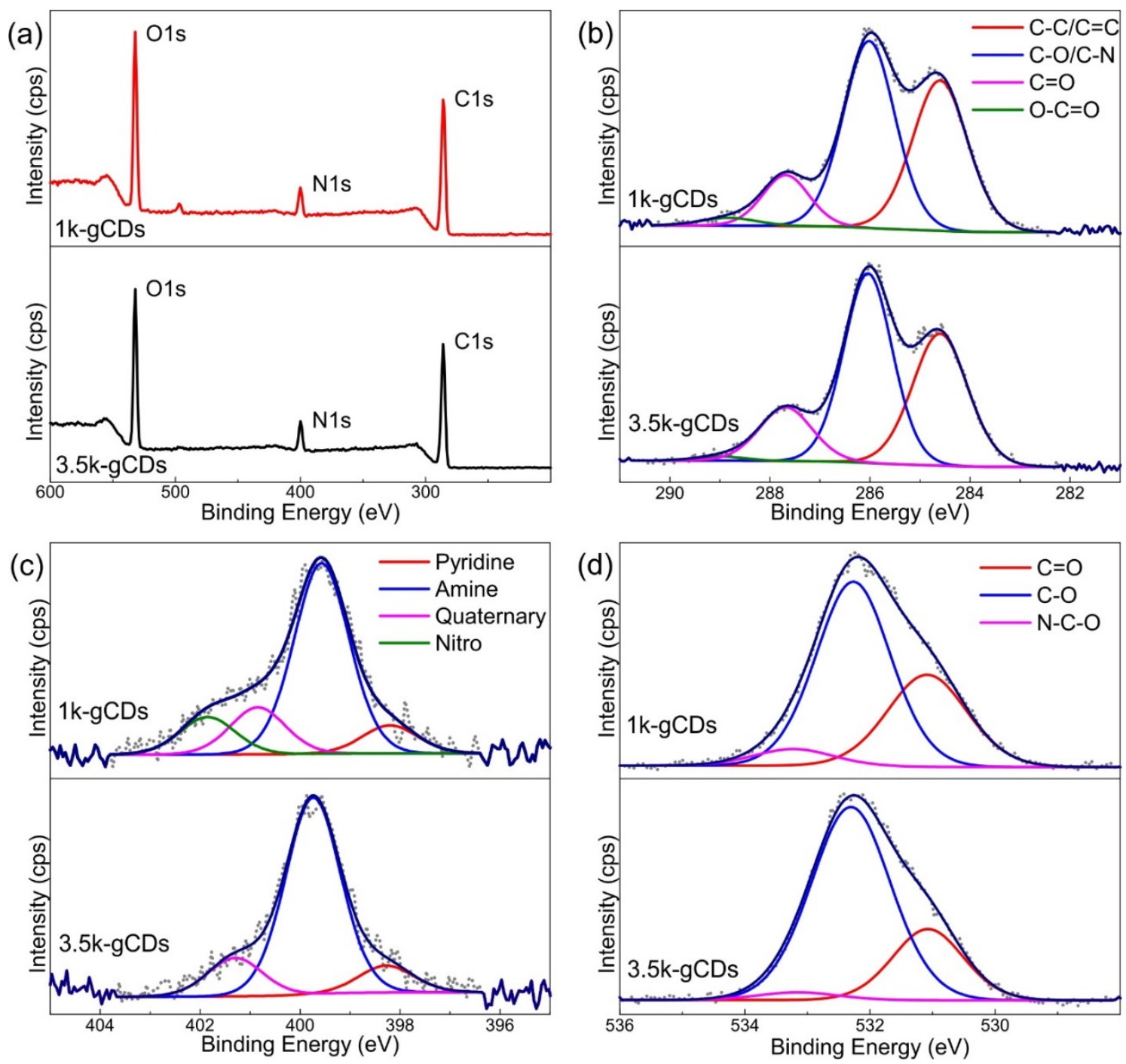

Figure S4 XPS (a) survey spectra, high resolution (b) C1s, (c) N1s and (d) O1s spectra of fractionated gCDs. 

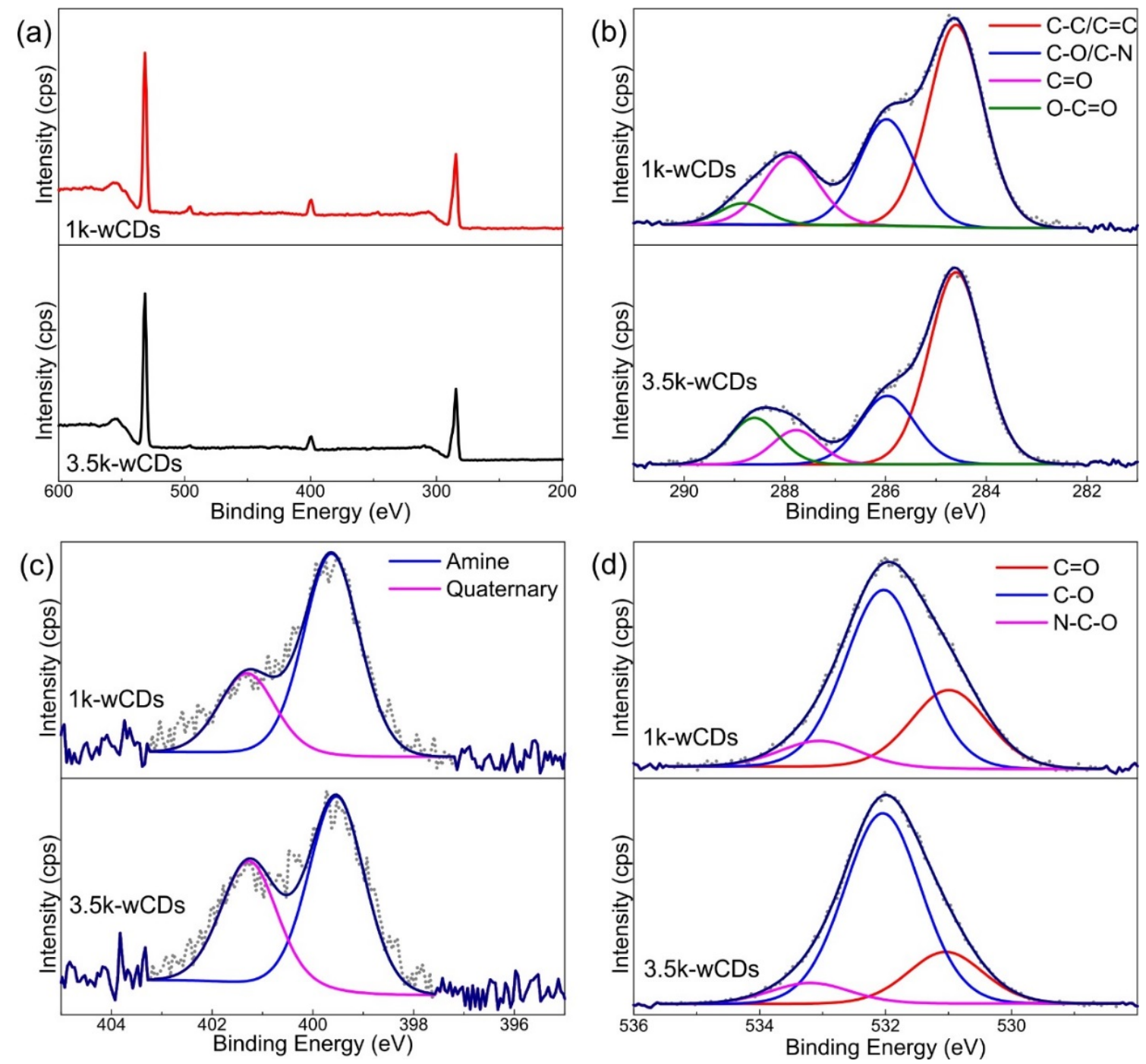

Figure S5 XPS (a) survey spectra, high resolution (b) C1s, (c) N1s and (d) O1s spectra of fractionated wCDs.

Table S1 Carbon, oxygen and nitrogen contents.

\begin{tabular}{cccc}
\hline Samples & C (At. \%) & N (At. \%) & O (At. \%) \\
\hline 1k-gCDs & 66.8 & 6.0 & 27.2 \\
3.5k-gCDs & 65.3 & 7.8 & 26.9 \\
1k-wCDs & 58.4 & 6.1 & 35.5 \\
$3.5 k-w C D s$ & 57.6 & 5.8 & 36.6 \\
\hline
\end{tabular}



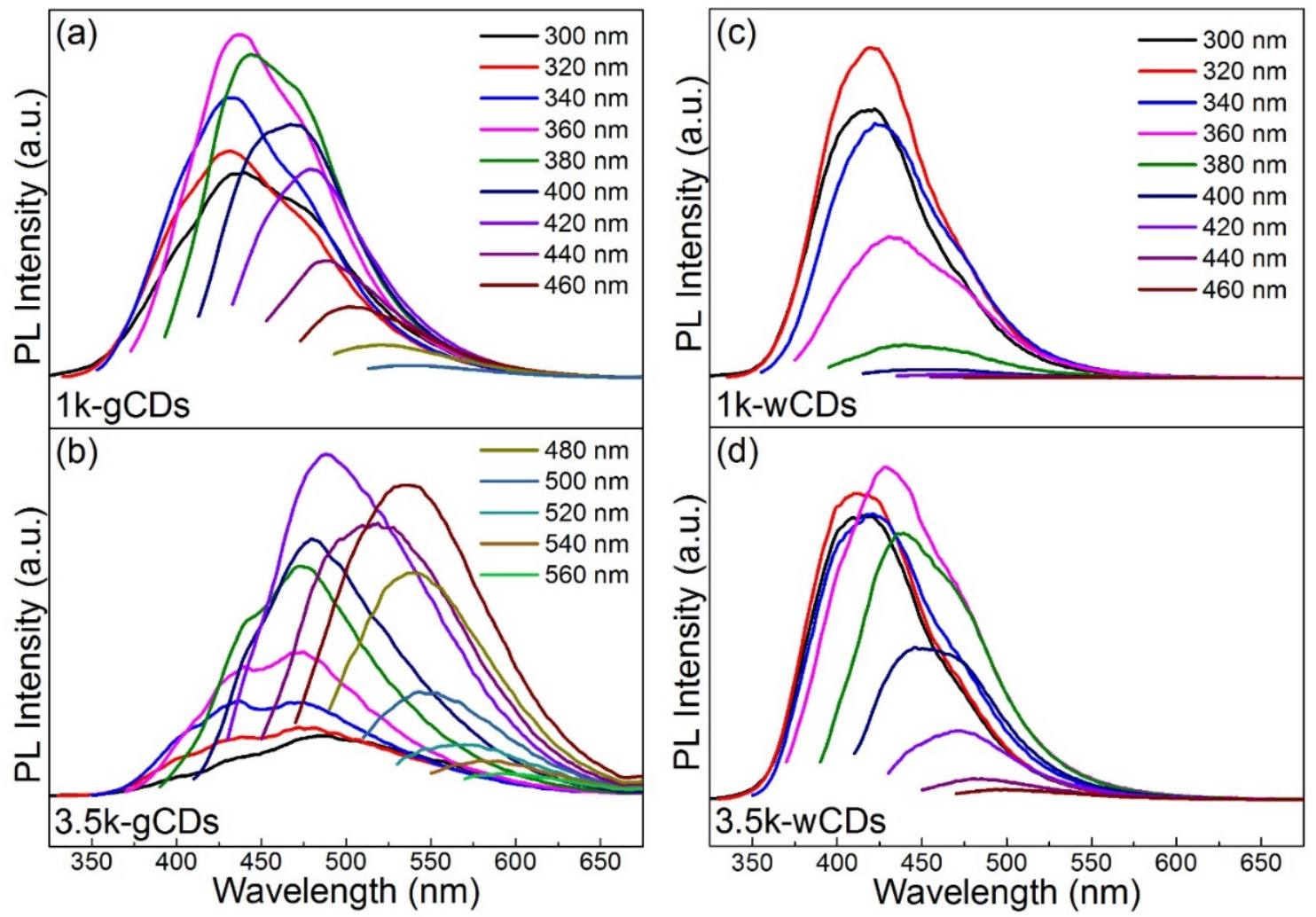

Figure S6 PL emission map of PL map of (a) 1k-gCDs, (b) 3.5k-gCDs, (c) 1k-wCDs and (d) 3.5k-wCDs. 


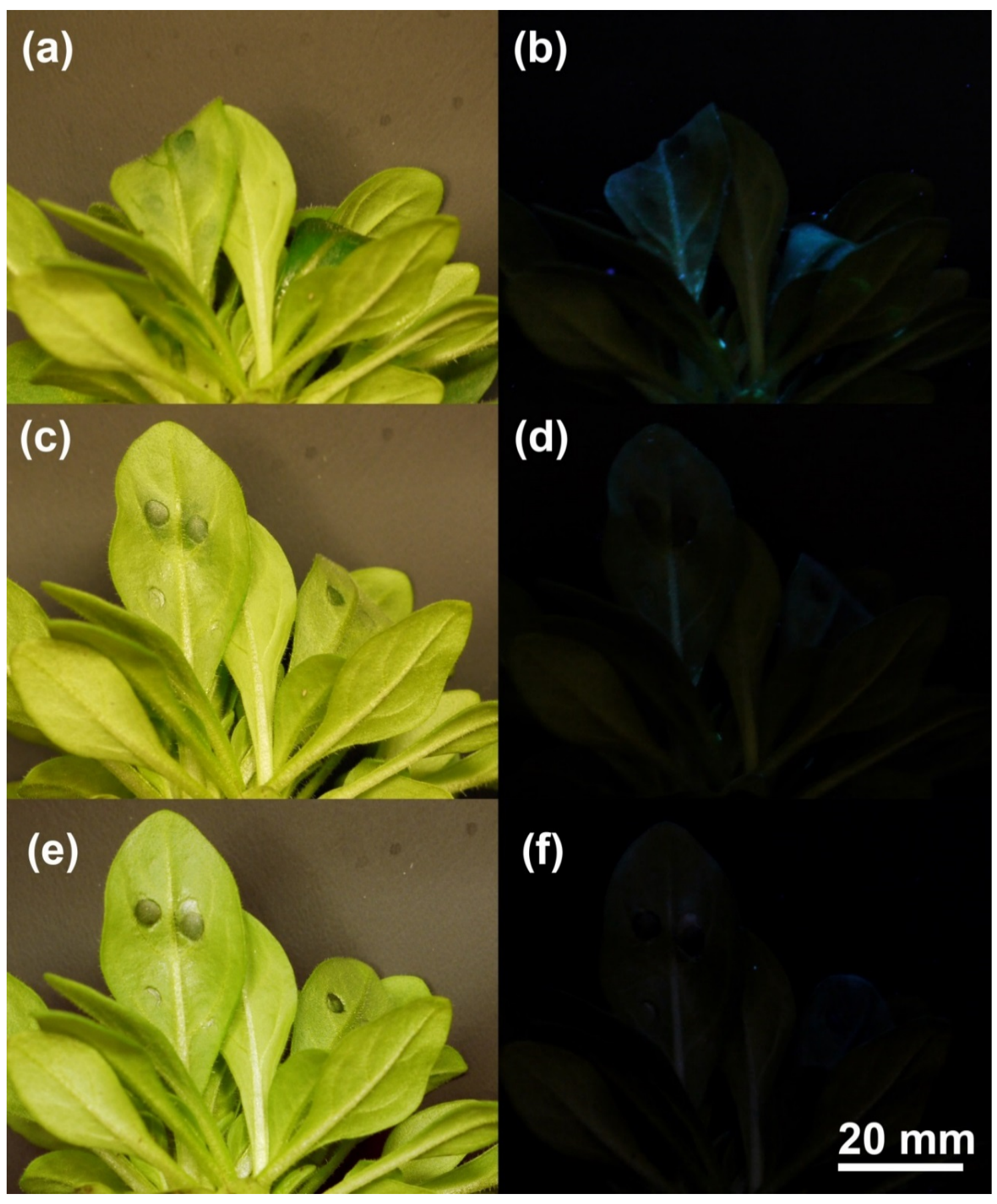

Figure S7 A leaf of a Petunia axillaris seedling infiltrated by 1k-gCDs after 10 min under (a) room light, (b) UV light, 2 hr under (c) room light, (d) UV light, 24 hr under (e) room light and (f) UV light. 


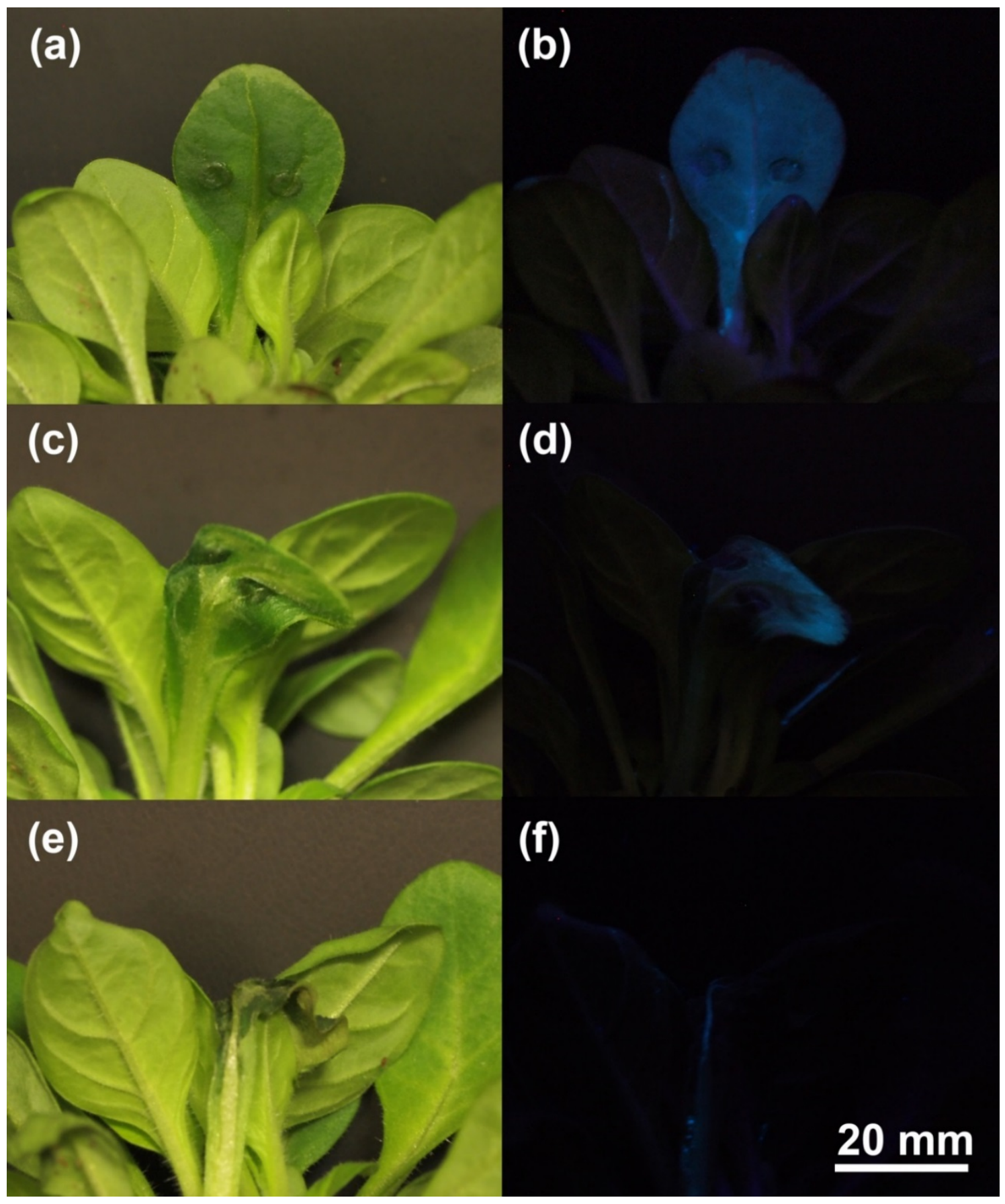

Figure S8 A leaf of a Petunia axillaris seedling infiltrated by 1k-wCDs after 10 min under (a) room light, (b) UV light, $2 \mathrm{hr}$ under (c) room light, (d) UV light, 24 hr under (e) room light and (f) UV light. 


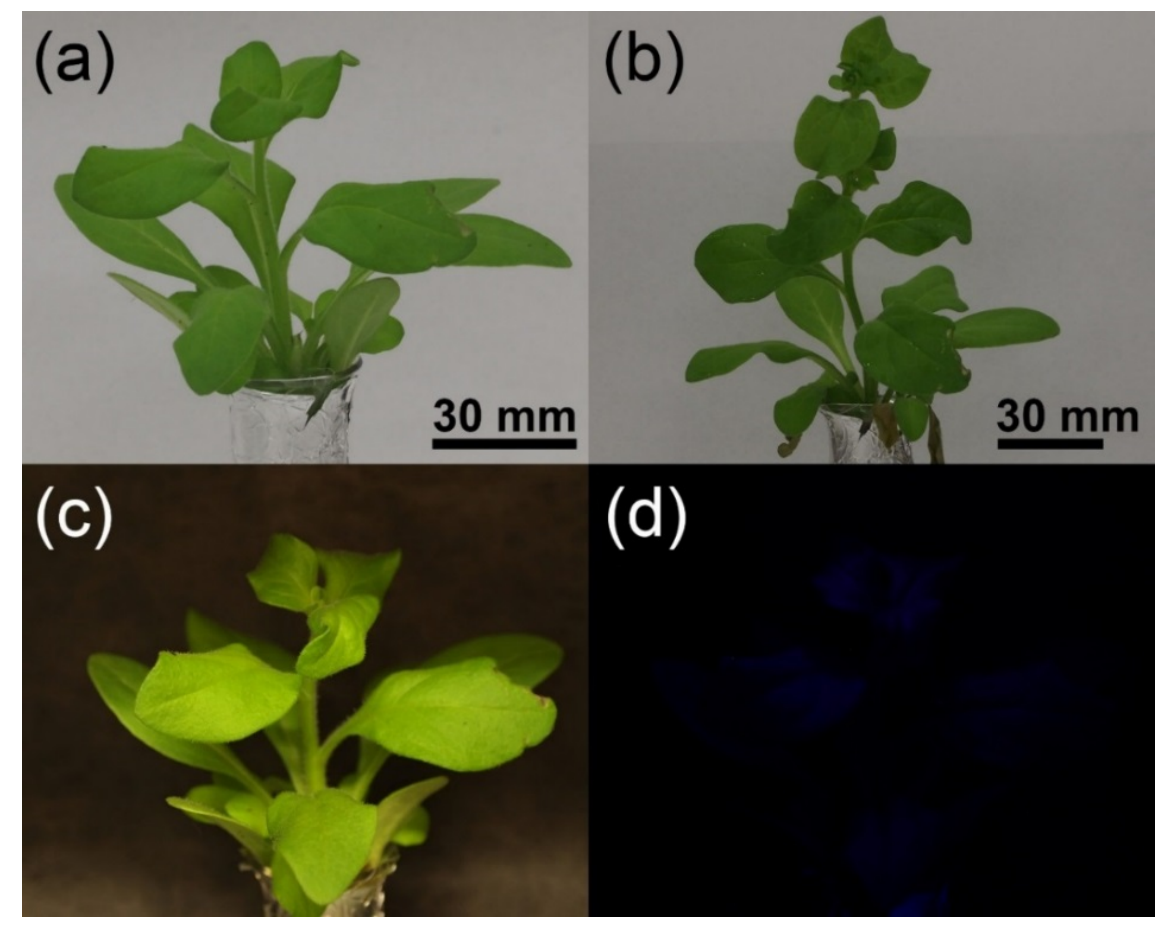

Figure S9 A Petunia axillaris seedling hydroponically grown by water for reference at (a) 0 week, (b) 4 weeks (c) 1 week under room light and (d) 1 week under UV light.

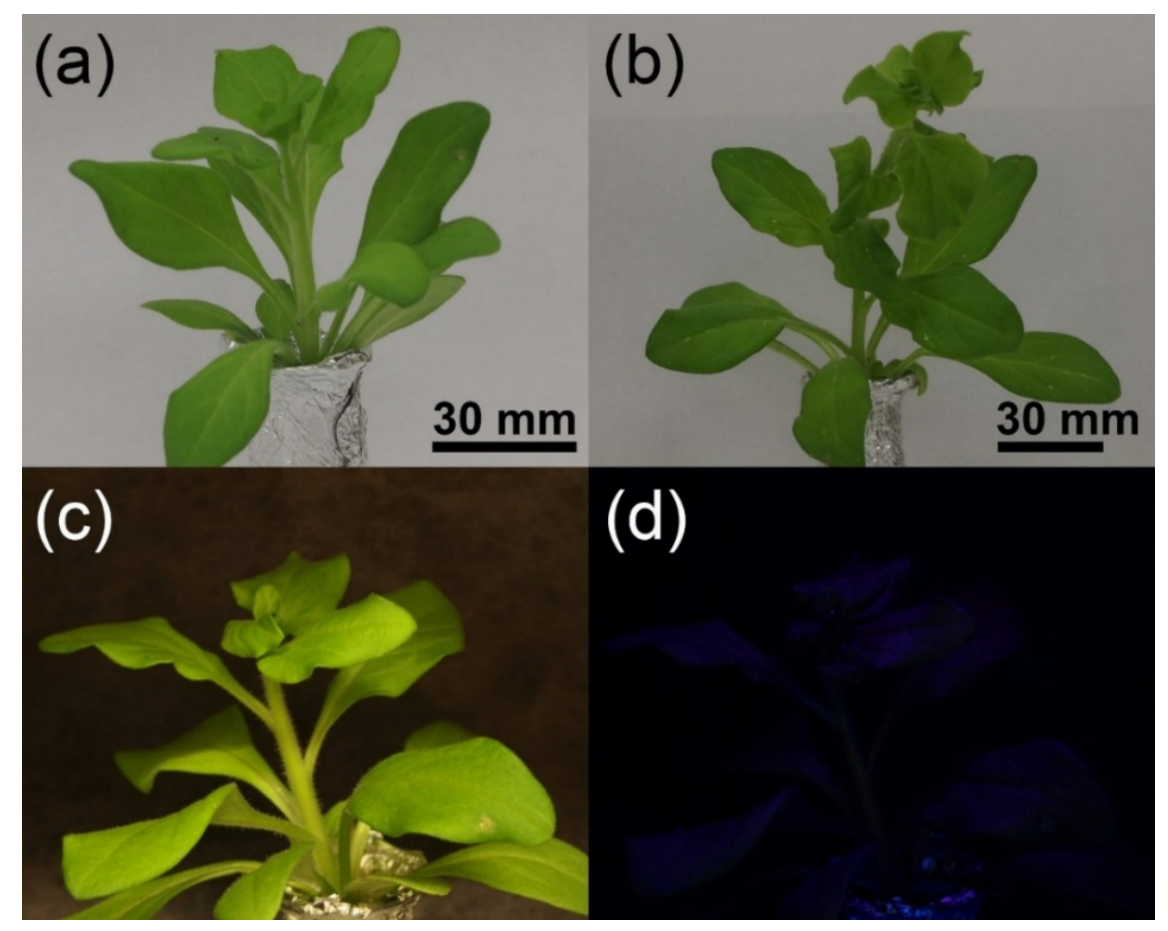

Figure S10 A Petunia axillaris seedling hydroponically grown by $1 \mathrm{k}$-gCD sample at (a) 0 week, (b) 4 weeks (c) 1 week under room light and (d) 1 week under UV light. 


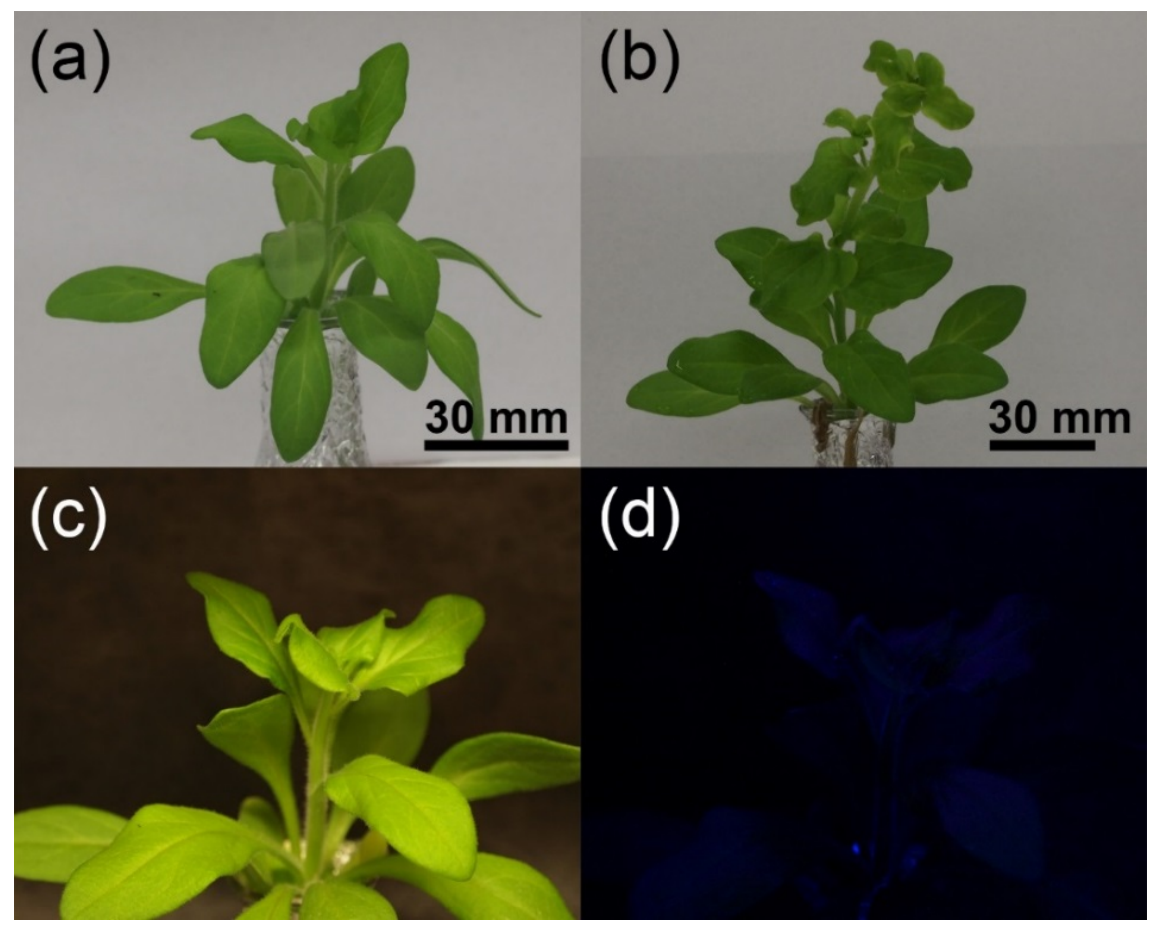

Figure S11 A Petunia axillaris seedling hydroponically grown by 1k-wCD sample at (a) 0 week, (b) 4 weeks (c) 1 week under room light and (d) 1 week under UV light.

The A Petunia axillaris seedlings grown in the presence of the CDs showed higher luminescent under UV. It was noticeable that the emission from the plants were close to that of the UV lamp. The emission of the plants was likely reflection of the UV light by trichomes on the seedlings. The seedlings grown by the CD samples might provide extra nutrients, resulting in a higher number of trichome growth on them compared to the control seedling. 
Table S2 Antibacterial test on 18 different bacterium species.

\begin{tabular}{llllllll}
\hline & \multicolumn{6}{c}{ Zone of inhibition (mm) } \\
\cline { 2 - 7 } $\begin{array}{llllll}\text { Bacteria } \\
\text { Species }\end{array}$ & $1 \mathrm{k}-\mathrm{gC}$ & $3.5 \mathrm{k}-\mathrm{g}$ & $1 \mathrm{k}-\mathrm{wCD}$ & $3.5 \mathrm{k}-\mathrm{w}$ & Ampicillin & Chloramphenicol & Negative \\
& $\mathrm{Ds}$ & $\mathrm{CDs}$ & $\mathrm{s}$ & $\mathrm{CDs}$ & (+ve control) & (+ve control) & control \\
\hline
\end{tabular}

\section{Gram-negative rods}

$\begin{array}{lcccccc}\text { A. faecalis } & - & - & - & - & 8 & - \\ \text { A hydrophilie } & - & - & - & - & 6 & 21 \\ \text { C. fruendi } & - & - & - & - & - & 19 \\ \text { E. coli0157 } & - & - & - & - & 6 & 19.5 \pm 0.71 \\ \text { K.pneumoniae } & - & - & - & - & - & - \\ \text { P. mirabilis } & - & - & - & - & 15 & 18 \\ \text { P. fluorescens } & - & - & - & - & - & 22 \\ \text { S. newport } & - & - & - & - & 9 & 7 \\ \text { S. marescens } & - & - & - & - & - & 19 \\ \text { S. sonei } & - & - & - & - & 8 & 6 \\ \text { E. } \text { gerogenes } & - & - & - & - & 8 & 21\end{array}$

Gram-negative bacilli

P. aeroginosa

A. baylyi

13

\section{Gram-positive rod}

B. cereus

\section{Gram-positive cocci}
S. aureus
S. epidermidis
S. pyogenes
E. faecalis

$8.5 \pm 0.71$ 

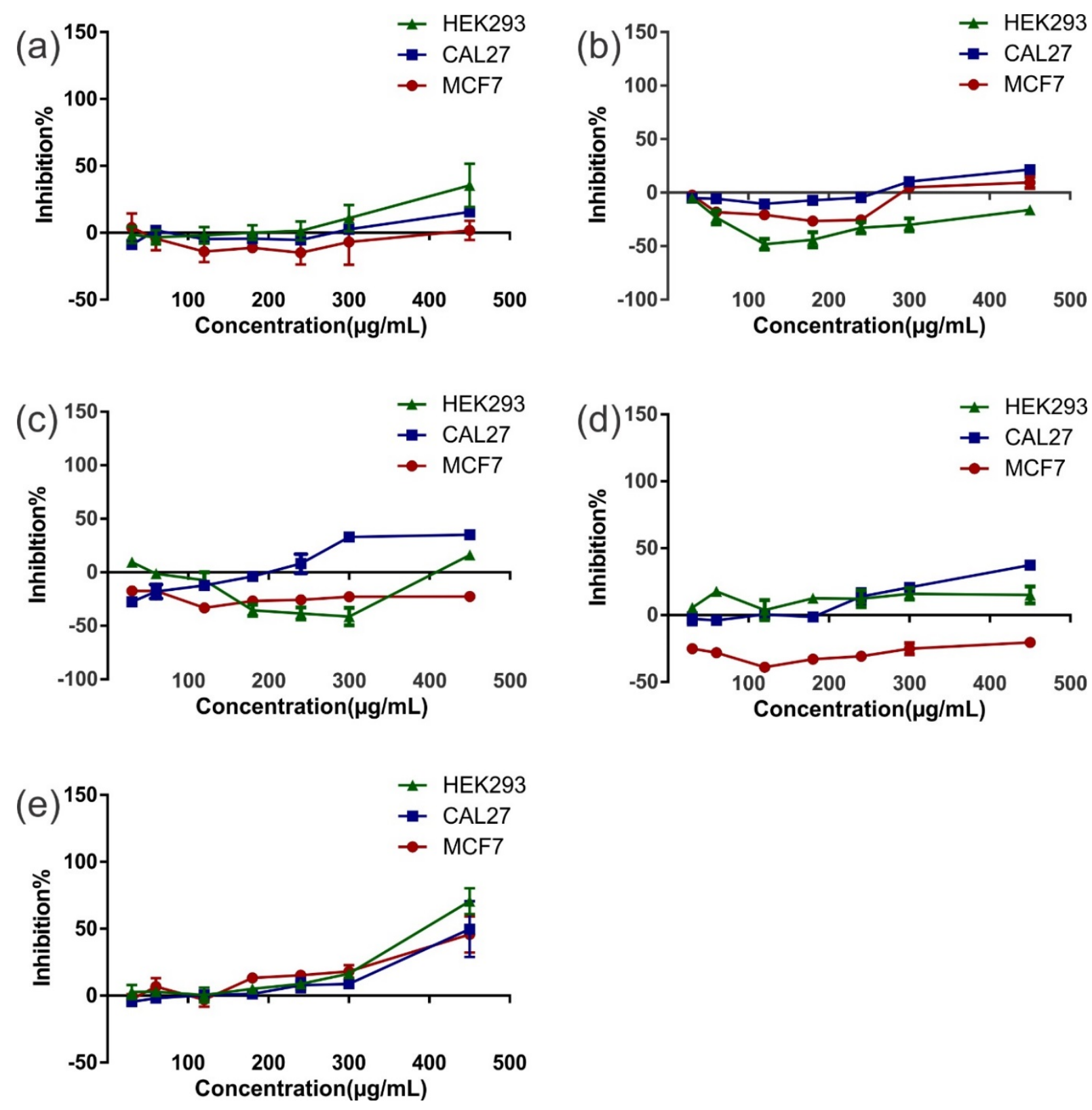

Figure S12 Dose response of human embryonic kidney cell line (HEK293), tongue squamous cell carcinoma cell line (CAL27) and human breast cancer cell line (MCF7) of (a) 1k-gCDs, (b) 3.5k-gCDs, (c) 1k-wCDs, (d) 3.5k-wCDs and (e) dose response of $1 \mathrm{k}$-gCDs assessed under shorter incubation periods (1k-gCDs introduced prior to the cell adhesion). 

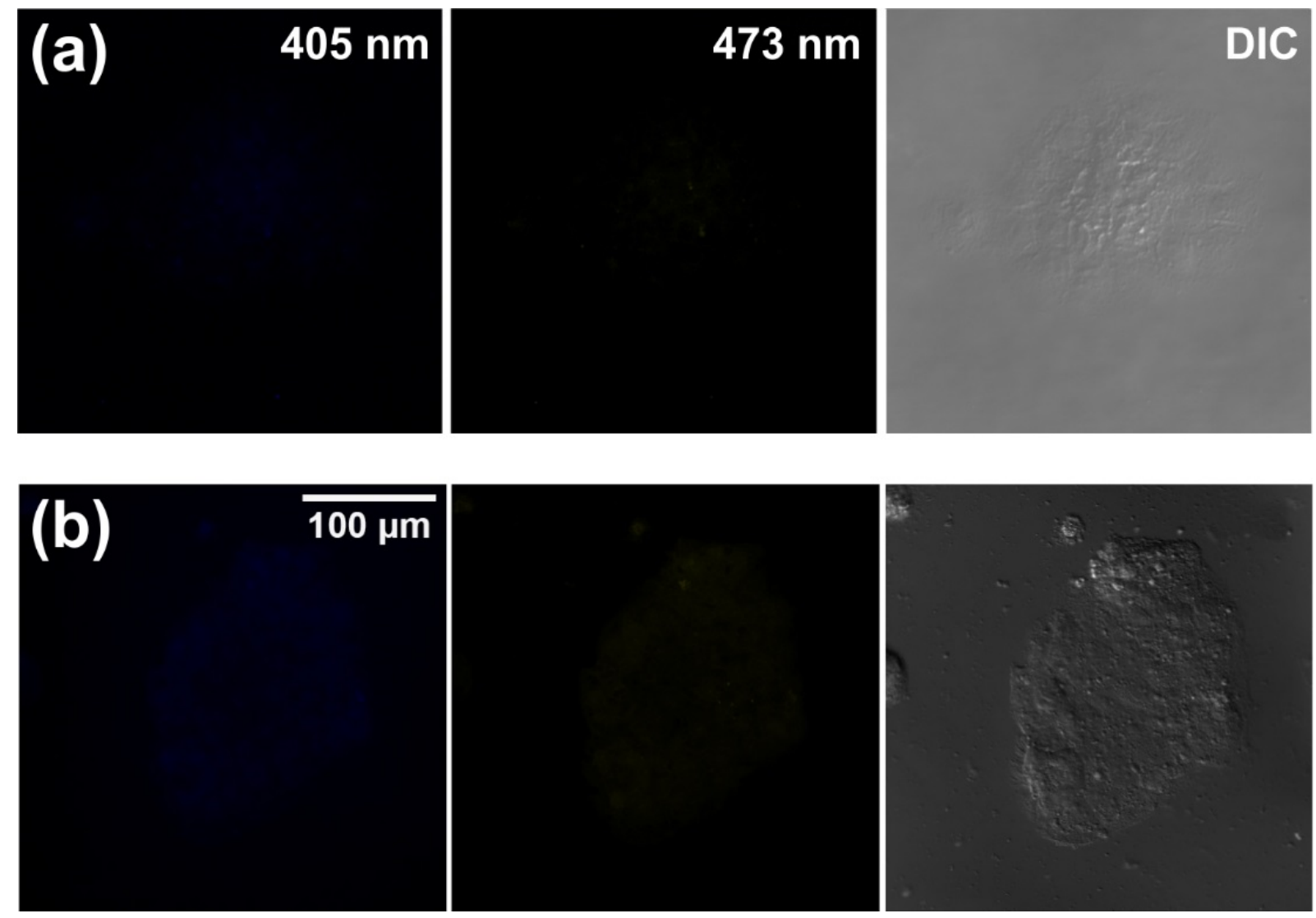

Figure S13 Confocal images of a control (a) JAr cell and (d) Jeg-3 cell incubated without 1k-gCDs (from left: image captured at 405, $473 \mathrm{~nm}$ and differential interference contrast image). 

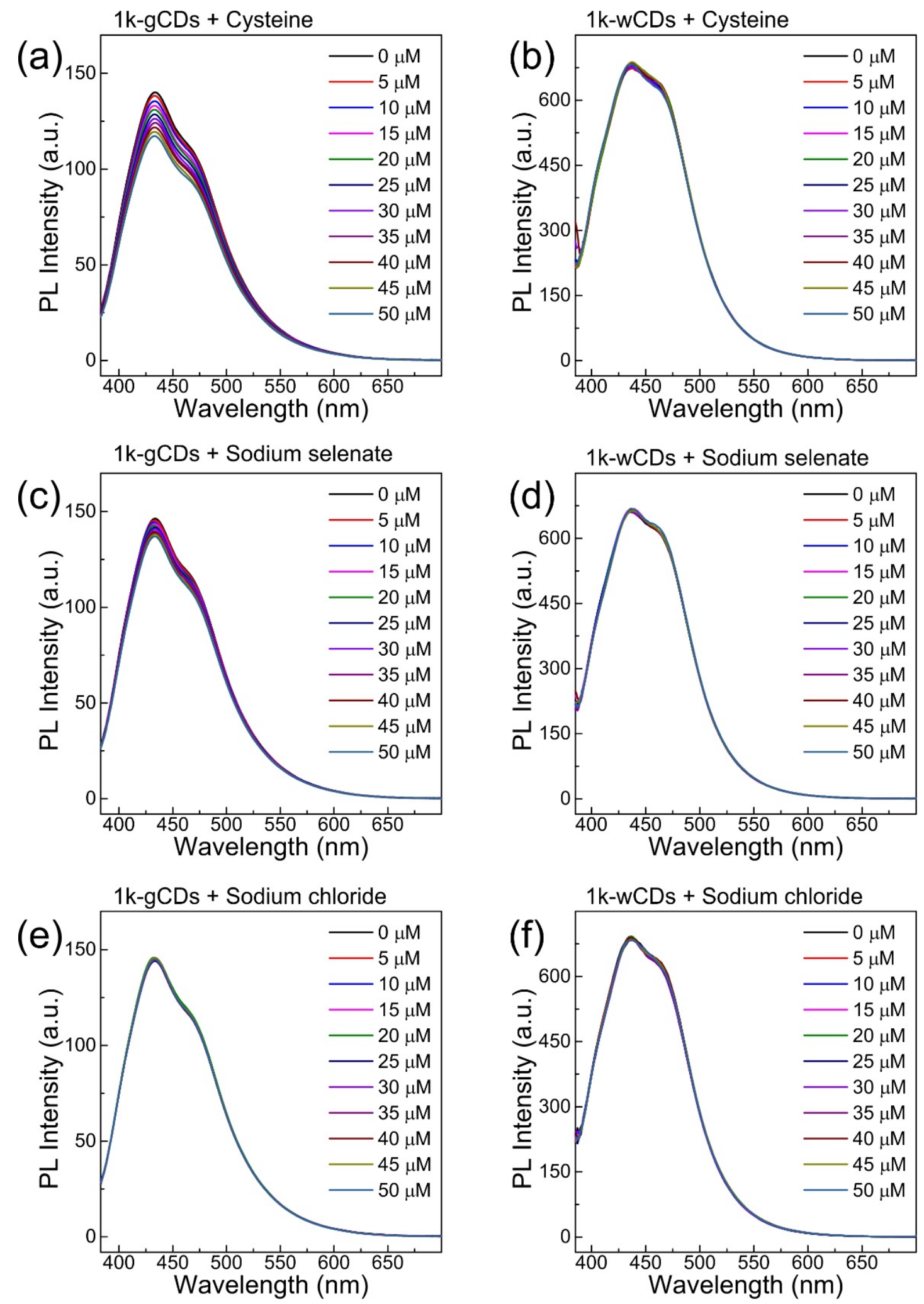

Figure S14 PL intensity responses of the 1k-CDs against (a), (b) sodium chloride, (c), (d) cysteine, (e) and (f) sodium selenate. (Left column: 1k-gCDs (a), (c), (e), right column: 1k-wCDs (b), (d), (f)). 


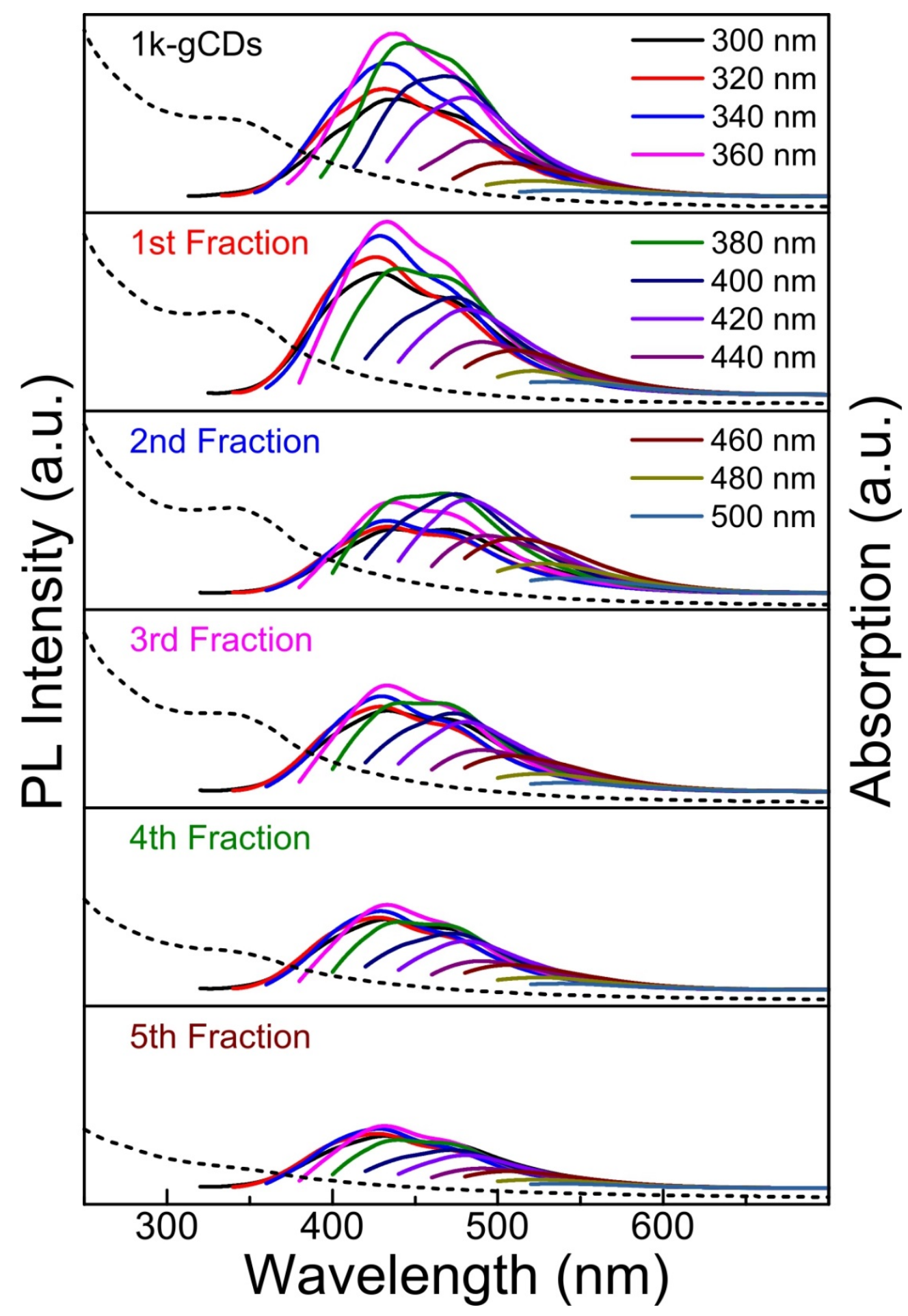

Figure S15 Optical properties of the column fractionated 1k-gCDs. 
(a) $1 \mathrm{k}-\mathrm{gCDs}{ }^{1 \mathrm{st}}+$ Cysteine

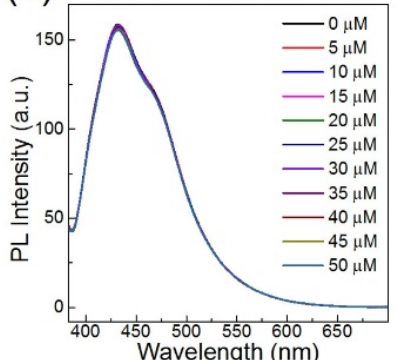

(b) $1 \mathrm{k}-\mathrm{gCDs} \mathrm{s}^{2 \mathrm{nd}}+$ Cysteine

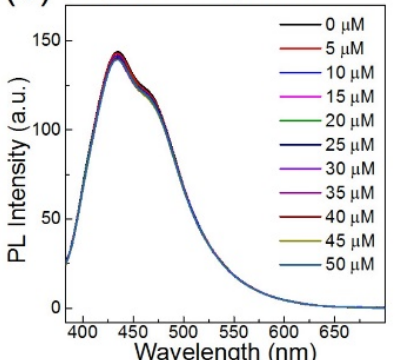

(C) $1 \mathrm{k}-\mathrm{gCDs} \mathrm{s}^{3 \mathrm{rd}}+$ Cysteine

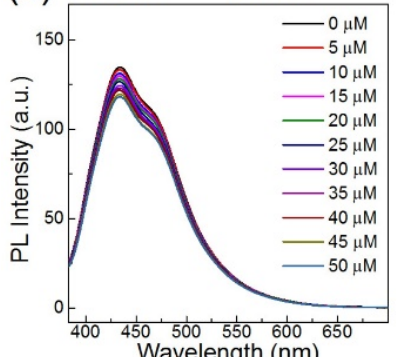

(d) $1 \mathrm{k}-\mathrm{gCDs} \mathrm{s}^{4 \text { th }}+$ Cysteine

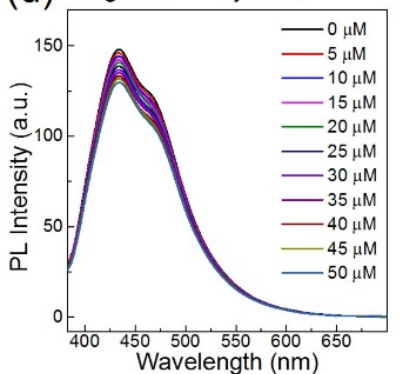

(e) $1 \mathrm{k}-\mathrm{gCDs} \mathrm{s}^{5 \mathrm{th}}+$ Cysteine

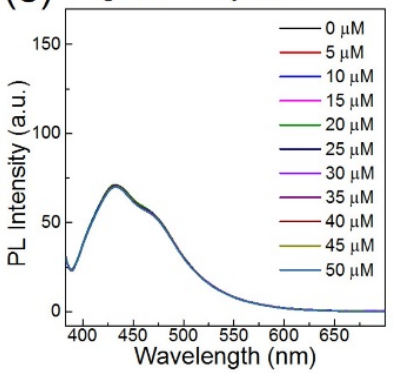

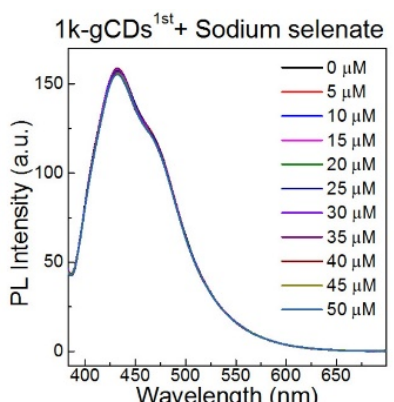
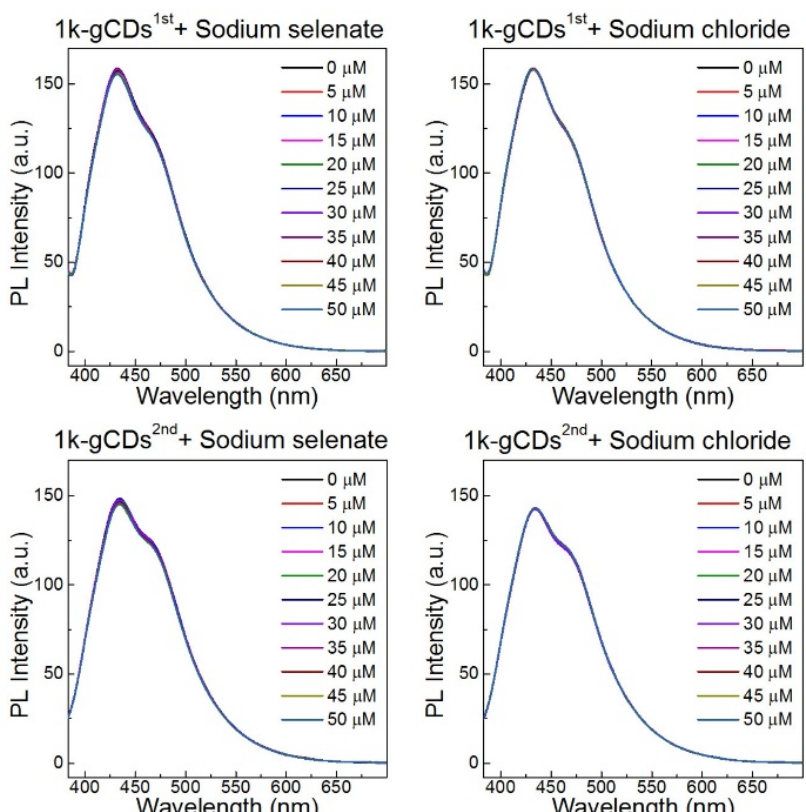

$1 \mathrm{k}-\mathrm{gCD} \mathrm{s}^{2 \mathrm{nd}}+$ Sodium chloride
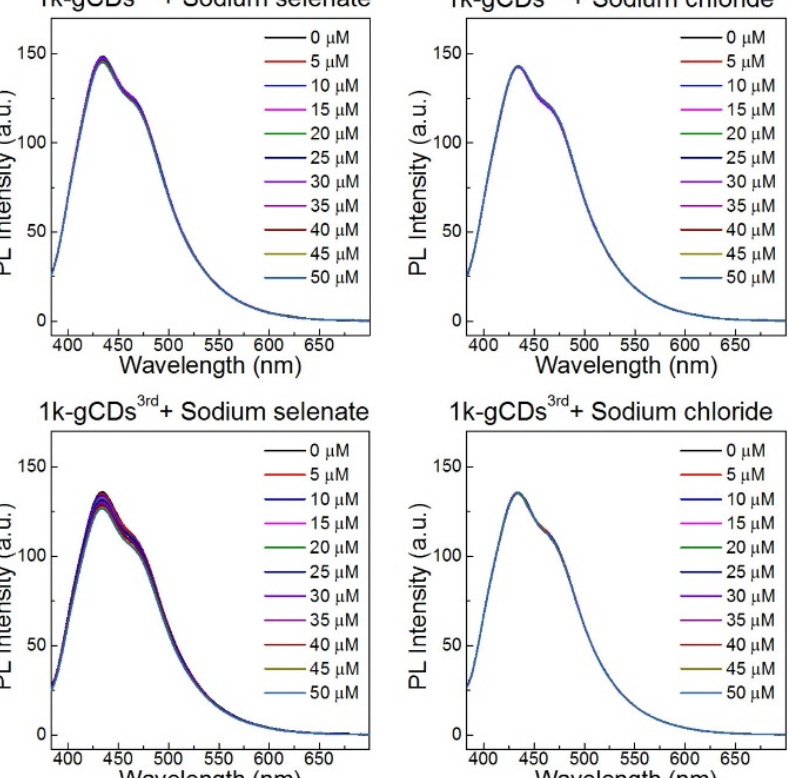

$1 \mathrm{k}-\mathrm{gCDs}{ }^{3 \mathrm{rd}}+$ Sodium chloride

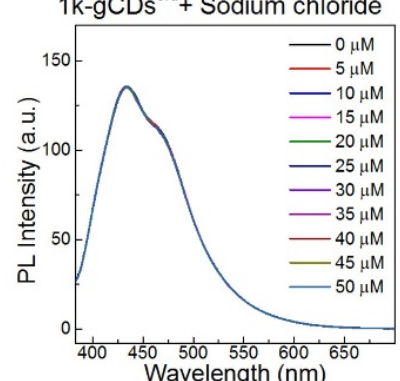

$1 \mathrm{k}-\mathrm{gCDs} \mathrm{s}^{4 \text { th }}+$ Sodium selenate
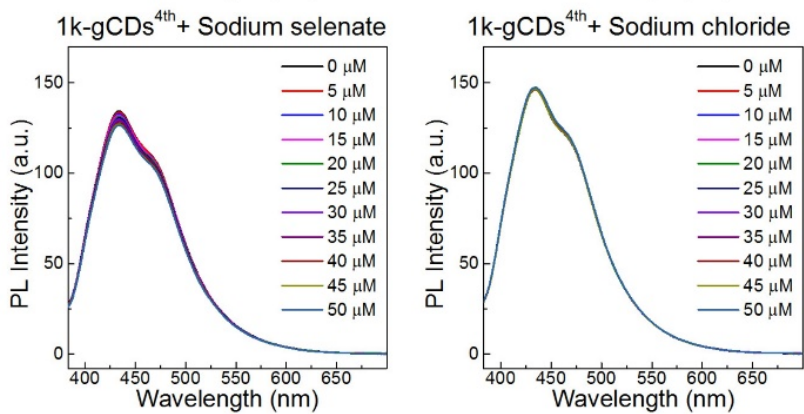

$1 \mathrm{k}-\mathrm{gCDs}{ }^{5 \text { th }}+$ Sodium selenate

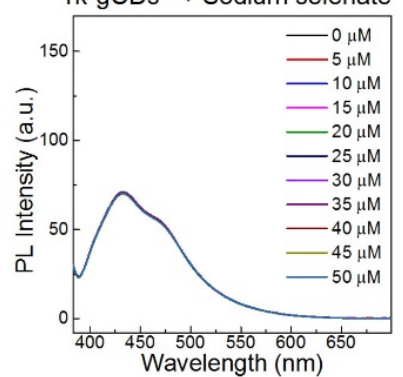

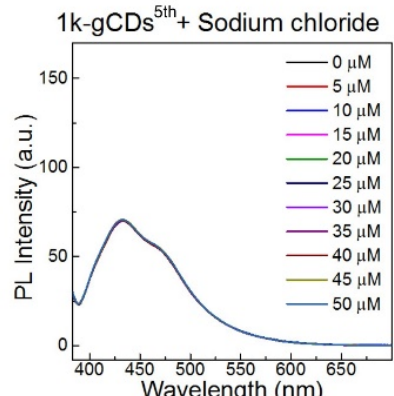

Figure S16 PL intensity responses of the fractionated 1k-gCDs against the analytes assessed. (a) 1k-gCDs ${ }^{1 s t}$, (b) $1 \mathrm{k}-g \mathrm{CDs}^{2 \mathrm{nd}}$, (c) $1 \mathrm{k}-\mathrm{gCDs} \mathrm{s}^{3 \mathrm{rd}}$, (d) $1 \mathrm{k}-\mathrm{gCDs}{ }^{\text {th }}$ and (e) $1 \mathrm{k}-\mathrm{gCDs}{ }^{5 \mathrm{th}}$ against $1^{\text {st }}$ column: cysteine, $2^{\text {nd }}$ column: sodium selenate and $3^{\text {rd }}$ column: sodium chloride. 